$12-2002$

\title{
The Effect of Convection on Disorder in Primary Cellular and Dendritic Arrays
}

R. Trivedi

Tollowstate enfivefdltyonal works at: https://engagedscholarship.csuohio.edu/encbe_facpub Part of the Materials Science and Engineering Commons, and the Transport Phenomena Commons
P. Mazumder cowning inc. access to this work benefit you? Let us know!

\section{Publisher's Statement}

Eurengy Cleveland State University

Transactions A: Physical Metallurgy and Materials Science, Vol. 33, Issue 12, pp. 3763-3775 and

is made available as an electronic reprint with the permission of ASM International. One print or electronic copy may be made for personal use only. Systematic or multiple reproduction, distribution to multiple locations via electronic or other means, duplications of any material in this paper for a fee or for commercial purposes, or modification of the content of this paper are prohibited.

Available on publisher's site at: http://hts.asminternational.org/portal/site/www/AsmStore/ ProductDetails/?vgnextoid=a5ea9163991e5210VgnVCM100000621e010aRCRD.

\section{Original Citation}

Trivedi, R., Mazumder, P., \& Tewari, S.N. (2002). The Effect of Convection on Disorder in Primary Cellular and Dendritic Arrays. Metallurgical and Materials Transactions A: Physical Metallurgy and Materials Science 33, 3763-3775.

\section{Repository Citation}

Trivedi, R.; Mazumder, P.; and Tewari, Surendra N., "The Effect of Convection on Disorder in Primary Cellular and Dendritic Arrays" (2002). Chemical \& Biomedical Engineering Faculty Publications. 14.

https://engagedscholarship.csuohio.edu/encbe_facpub/14

This Article is brought to you for free and open access by the Chemical \& Biomedical Engineering Department at EngagedScholarship@CSU. It has been accepted for inclusion in Chemical \& Biomedical Engineering Faculty Publications by an authorized administrator of EngagedScholarship@CSU. For more information, please contact library.es@csuohio.edu. 


\title{
The Effect of Convection on Disorder in Primary Cellular and Dendritic Arrays
}

\author{
R. TRIVEDI, P. MAZUMDER, and S.N. TEWARI
}

\begin{abstract}
Directional solidification studies have been carried out to characterize the spatial disorder in the arrays of cells and dendrites. Different factors that cause array disorder are investigated experimentally and analyzed numerically. In addition to the disorder resulting from the fundamental selection of a range of primary spacings under given experimental conditions, a significant variation in primary spacings is shown to occur in bulk samples due to convection effects, especially at low growth velocities. The effect of convection on array disorder is examined through directional solidification studies in two different alloy systems, $\mathrm{Pb}-\mathrm{Sn}$ and $\mathrm{Al}-\mathrm{Cu}$. A detailed analysis of the spacing distribution is carried out, which shows that the disorder in the spacing distribution is greater in the Al-Cu system than in $\mathrm{Pb}-\mathrm{Sn}$ system. Numerical models are developed which show that fluid motion can occur in both these systems due to the negative axial density gradient or due the radial temperature gradient which is always present in Bridgman growth. The modes of convection have been found to be significantly different in these systems, due to the solute being heavier than the solvent in the Al-Cu system and lighter than it in the $\mathrm{Pb}-\mathrm{Sn}$ system. The results of the model have been shown to explain experimental observations of higher disorder and greater solute segregation in a weakly convective Al-Cu system than those in a highly convective $\mathrm{Pb}-\mathrm{Sn}$ system.
\end{abstract}

\section{INTRODUCTION}

ONE of the important microstructural length scales of directionally solidified alloys is the primary spacing, or the periodicity, of the cellular and dendritic structures. This periodicity often controls the microsegregation profiles and governs the formation of a second phase in the intercellular or interdendritic regions and, consequently, influences the properties of the material. Several theoretical and experimental studies have, thus, been carried out to relate primary spacing to the growth rate, temperature gradient, and composition. ${ }^{[1-16]}$ Although the average spacing is most often reported in the literature, experimental studies show that a significantly broad spectrum of primary spacings is present. ${ }^{[6]}$ This disorder in spacings can occur due to two factors: a weak spacing-selection criterion, which causes a range of spacings to be present, and the effect of convection in large or bulk samples.

Fundamental studies on the distribution of primary spacings under diffusive-growth conditions have been carried out theoretically as well as experimentally. Warren and Langer ${ }^{[2]}$ have developed a diffusive-boundary-layer model which predicted that the primary dendrite spacing would not have a unique value under given growth conditions. Rather, a band of primary spacings would be stable. A similar conclusion was reached by Hunt and $\mathrm{Lu}^{[4]}$ through a detailed numerical solution of the primary-spacing problem. They concluded that the maximum spacing would be less than a factor of 2 from the minimum spacing; otherwise, a new cell or dendrite

R. TRIVEDI, Professor, is with the Department of Materials Science and Engineering, Iowa State University, Ames, IA 50011. Contact e-mail: trivedi@ameslab.gov P. MAZUMDER, formerly Graduate Student, Department of Mechanical Engineering, Iowa State University, is Research Scientist with Corning Inc., Corning, NY 14831. S.N. TEWARI, Professor, is with the Chemical Engineering Department, Cleveland State University, Cleveland, $\mathrm{OH} 44115$.

Manuscript submitted June 1, 1999. with a minimum spacing would be created. Thus, the spacing distribution under given growth conditions should, at most, be within a factor of 2 if diffusive growth conditions are present.

Detailed experimental studies, carried out in thin samples of a transparent material in which the primary spacing is controlled by the diffusion process, have confirmed the presence of a finite but small range of spacings under given growth conditions. ${ }^{[6]}$ Through studies of the dynamics of spacing adjustments, it was shown that cells can translate laterally to minimize the disorder, and a new cell or dendrite was created when the spacing exceeded about 1.5 times the minimum stable spacing. ${ }^{[6]}$ In contrast to the previous results, experimental studies in bulk metallic and organic systems have clearly shown the presence of a wide range of spacings or a highly disordered spatial arrangement of cells and dendrites. Convection effects have been assumed to be responsible for this large disorder in bulk samples. ${ }^{[5,11]}$ For primaryspacing studies, larger-diameter samples in the range of 3.0 to $7.0 \mathrm{~mm}$ are generally used to obtain sufficient number of primary cells or dendrites required for a proper statistical analysis. However, as the size of the sample increases, the possibility for convection increases. In fact, for the $\mathrm{Al}-\mathrm{Cu}$ system, convective transport can become greater than or equal to the diffusive transport under $1 \mathrm{~g}$ conditions, for sample diameters greater than $3 \mathrm{~mm} \cdot{ }^{[17,18]}$ Thus, it is possible for convection effects to give rise to the disorder in spacing.

The effect of convection on the disorder in spatial arrangement of dendrites was established by comparing the primary dendrite arrays formed under $1 \mathrm{~g}$ and microgravity conditions for the same growth conditions in an $\mathrm{Al}-4$ wt pct $\mathrm{Cu}$ alloy ${ }^{[19]}$ A result of one microgravity experiment ${ }^{[19]}$ showed a significantly smaller disorder in spacings. However, only a few dendrites were present in the sample processed under microgravity conditions, so that no quantitative analysis of the primary-spacing disorder under diffusive-growth conditions could be carried out. 
In the vertical Bridgman growth technique, convection effects depend on the spatial variation of the density of the melt, so that systems with different density variations with solute will show different effects on the spacing distribution. Experimental studies in several systems in which the rejected solute was heavier than the solvent have shown that fluid flow leads to the presence of a macroscopic interface which protrudes at the center and leads to a nonuniform microstructure along the radial direction. ${ }^{[1,20,21]}$ However, in systems where the rejected solute is lighter, no appreciable curvature of the interface is observed, even when convection effects are present in the melt. In this case, although the spacing will be significantly influenced by convection, a smaller disorder in spacing should be present. Although convection effects have been assumed to give rise to a disorder in spacing, no theoretical or experimental study has been carried out to quantitatively characterize how the nature of convection gives rise to array disorder.

A proper quantitative understanding of the effect of convection on the disorder in spacings is important, since the properties of a material depend not only on the average spacing but also on the extent of disorder in the primary array, which will locally influence the mushy-zone length and the segregation profile. In this article, we shall first present experimental results on the primary-spacing distribution and then discuss a numerical model to show how convection effects may cause disorder in the primary spacing. When convection effects are present, the disorder in spacing depends upon the mode of convection, which is controlled by the properties of the system, specifically, the variation in fluid density with concentration. Experiments have, thus, been carried out in two alloy systems, $\mathrm{Pb}-\mathrm{Sn}$ and $\mathrm{Al}-\mathrm{Cu}$. These two systems were selected since then rejected solute is heavier in the Al- $\mathrm{Cu}$ system and lighter in the $\mathrm{Pb}-\mathrm{Sn}$ system, so that they exhibit different modes of convection. Experimental results showed that the disorder in the $\mathrm{Al}-\mathrm{Cu}$ system was significantly greater than that in the $\mathrm{Pb}-\mathrm{Sn}$ system. In addition, the disorder was found to remain over a wide range of velocities examined.

In the $\mathrm{Pb}-\mathrm{Sn}$ system, the rejected solute at the interface is lighter than the solvent, which can result in a significant fluid motion due to double diffusive instability. ${ }^{[22,23,24]}$ In contrast, in the $\mathrm{Al}-\mathrm{Cu}$ system, the rejected solute at the interface is heavier and will give rise to a negative density gradient in the liquid at the interface, which will result in no fluid motion in the absence of other destabilizing forces. Although vertical thermal and solute gradients do not cause fluid motion in the $\mathrm{Al}-\mathrm{Cu}$ system, convection can still be present in this system if there is any thermal gradient in the radial direction, since there is no threshold for convection in the presence of a radial temperature or concentration gradient. ${ }^{[25,26]}$ In fact, a radial temperature gradient is always present in Bridgman growth, in which the hot and the cold chambers are separated by an insulating region. ${ }^{[17,27-32]} \mathrm{A}$ detailed numerical analysis of convection is, therefore, carried out for both the systems to characterize the fluid motion and the composition profiles. The results of this numerical model will be presented in this article, and it will be shown that the lower level of convection in the Al-Cu system comes from the radial temperature gradient, which causes radial solute segregation and, hence, leads to higher disorder in the primary-spacing distribution. In contrast, the intensive
Table I. Growth Parameters for Directionally Solidified $\mathrm{Pb}-\mathrm{Sn}$ and Al-Cu Alloys

\begin{tabular}{|c|c|c|c|c|}
\hline Alloy Specimen & $\begin{array}{l}\text { Velocity } \\
(\mu \mathrm{m} / \mathrm{s})\end{array}$ & $\begin{array}{l}\text { Thermal } \\
\text { Gradient } \\
(\mathrm{K} / \mathrm{mm})\end{array}$ & $\begin{array}{c}\text { W-S } \\
\text { Diameter } \\
(\mu \mathrm{m})\end{array}$ & Morphology \\
\hline 1. $\mathrm{Pb}-10$ wt pct $\mathrm{Sn}$ & 2.0 & 11.0 & - & cell \\
\hline 2. $\mathrm{Pb}-10$ wt pet $\mathrm{Sn}$ & 2.5 & 11.0 & 122 & cell \\
\hline 3. $\mathrm{Pb}-10$ wt pet $\mathrm{Sn}$ & 3.5 & 11.0 & 135 & cell \\
\hline 4. $\mathrm{Pb}-10$ wt pct $\mathrm{Sn}$ & 4 & 11.0 & 142 & cell to dendrite \\
\hline 5. $\mathrm{Pb}-10$ wt pet $\mathrm{Sn}$ & 8 & 11.0 & 130 & dendrite \\
\hline 1. $\mathrm{Al}-4.1 \mathrm{wt}$ pet $\mathrm{Cu}$ & 1.83 & 10.0 & - & cell \\
\hline 2. Al-4.1 wt pet $\mathrm{Cu}$ & 2.8 & 14.0 & - & cell \\
\hline 3. Al-4.1 wt pet $\mathrm{Cu}$ & 5.5 & 14.0 & 97 & cell \\
\hline 4. $\mathrm{Al}-4.1$ wt pet $\mathrm{Cu}$ & 11 & 14.0 & 106 & cell \\
\hline 5. Al-4.1 wt pet $\mathrm{Cu}$ & 22 & 14.0 & 163 & cell to dendrite \\
\hline 6. Al-4.1 wt pet $\mathrm{Cu}$ & 44 & 14.0 & 161 & dendrite \\
\hline
\end{tabular}

double-diffusive mode of convection in the $\mathrm{Pb}$-Sn system gives homogeneous solute segregation in the radial direction and, thus, causes less disorder in the spacing.

\section{EXPERIMENTAL STUDIES}

\section{A. Microstructures}

Directional solidification experiments were carried out in the Al-4.1 wt pet $\mathrm{Cu}, \mathrm{Al}-4.0$ wt pet $\mathrm{Cu}$, and $\mathrm{Pb}-10$ wt pct Sn alloys using the sample preparation procedure and directional solidification equipment described previously. ${ }^{[33]}$ For Al-Cu alloys, 6-mm-i.d. recrystallized alumina tubes were used, whereas 7-mm-i.d. quartz tubes were used for the $\mathrm{Pb}$ Sn alloys, and the melt column was about $20-\mathrm{cm}$ long. The total sample length was about $30 \mathrm{~cm}$. Precast $\mathrm{Al}-\mathrm{Cu}$ and $\mathrm{Pb}-\mathrm{Sn}$ samples were remelted and directionally solidified in a flowing argon atmosphere. Directional solidification was carried out by raising the thermal assembly at a fixed rate, keeping the sample tube fixed so as to avoid any possibility of fluid motion due to the irregular motion of the sample. The furnace assembly was moved at rates ranging from 0.70 to $44.0 \mu \mathrm{m} / \mathrm{s}$.

Different velocities were examined for each alloy system, as shown in Table I, and these velocities were selected to obtain both cellular and dendritic arrays and to examine the effect of convection with velocity. For A1-4.1 wt pct $\mathrm{Cu}$ alloys, the samples were directionally solidified at velocities of $2.6,5.5,11.0,22.0$, and $44.0 \mu \mathrm{m} / \mathrm{s}$, at $G=14.0 \mathrm{~K} / \mathrm{mm}$. Al-4.0 wt pet $\mathrm{Cu}$ alloys were directionally solidified at a velocity of $1.83 \mu \mathrm{m} / \mathrm{s}$, at $G=10.0 \mathrm{~K} / \mathrm{mm}$. The transverse cross sections of the directionally solidified samples are shown in Figure 1, which shows a cellular structure at two lower velocities, a transition to a dendritic microstructure at $22.0 \mu \mathrm{m} / \mathrm{s}$, and a fully dendritic structure at $44.0 \mu \mathrm{m} / \mathrm{s}$. Transverse sections in the mushy zone, $100 \mu \mathrm{m}$ behind the quenched tip, were used for the primary-arm spacing measurements.

The $\mathrm{Pb}-10$ wt pct $\mathrm{Sn}$ alloys were directionally solidified at velocities of $2.0,2.5,3.5,4.0$, and $8.0 \mu \mathrm{m} / \mathrm{s}$, at $G=11.0$ $\mathrm{K} / \mathrm{mm}$. The microstructures were cellular at growth speeds of $2.0,2.5$, and $3.5 \mu \mathrm{m} / \mathrm{s}$, displayed a transition to a dendritic microstructure at $4.0 \mu \mathrm{m} / \mathrm{s}$, and had a fully dendritic structure 


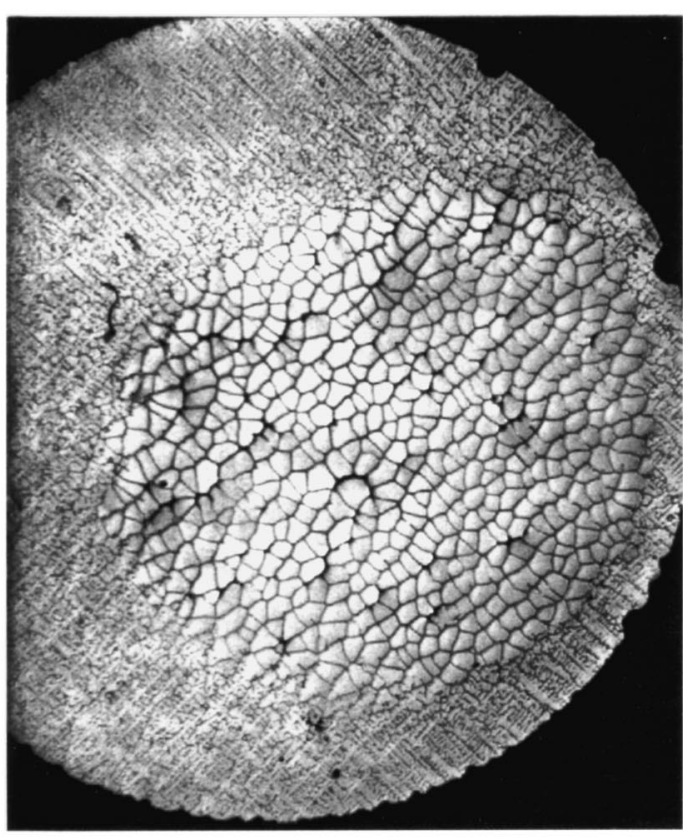

(a)

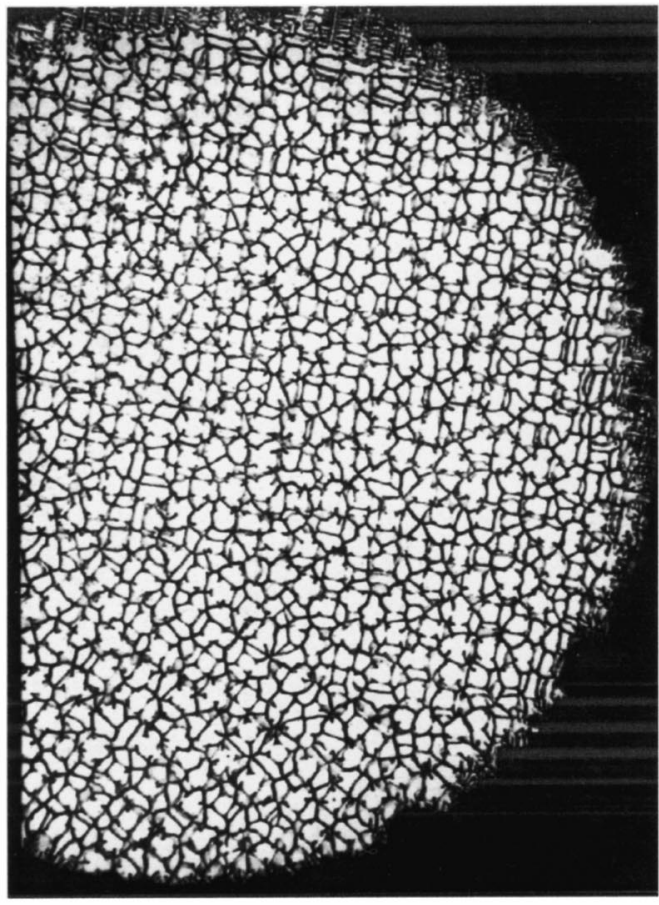

(c)

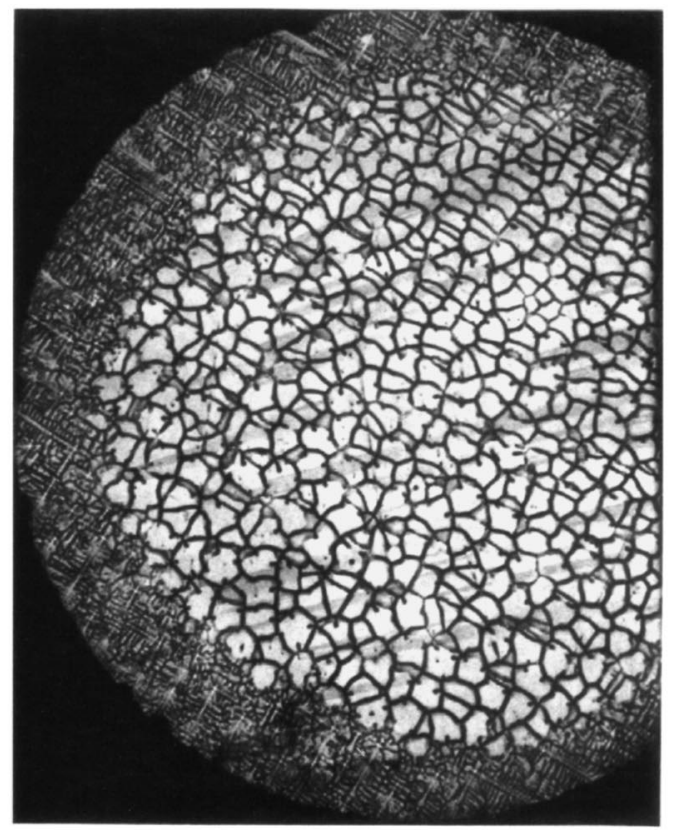

(b)

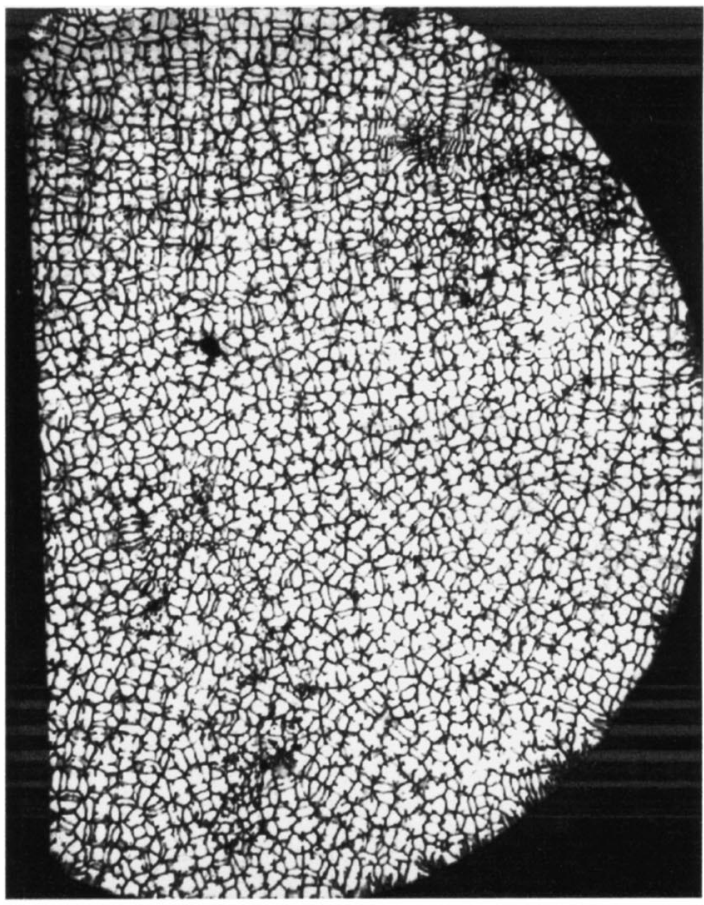

(d)

Fig. 1-Transverse microstructures of directionally solidified for Al-4.1 wt pct Cu alloys at velocities: (a) $5.5 \mu \mathrm{m} / \mathrm{s},(b) 11.0 \mu \mathrm{m} / \mathrm{s},(c) 22.0, \mu \mathrm{m} / \mathrm{s}$, and (d) $44.0, \mu \mathrm{m} / \mathrm{s} . G=14.0 \mathrm{~K} / \mathrm{mm}$.

at $8.0 \mu \mathrm{m} / \mathrm{s}$. A typical transverse section of the cellular structure is shown in Figure 2.

A comparison of transverse microstructures of directionally solidified $\mathrm{Pb}-10$ wt pet $\mathrm{Sn}$ and $\mathrm{Al}-4.1$ wt pet $\mathrm{Cu}$ alloys, shown in Figure 3, clearly illustrates the significant difference in the shape of the interface in these two systems. In the $\mathrm{Pb}-\mathrm{Sn}$ alloys, the array distribution shows that the macroscopic interface, i.e., the positions of tips, is aligned with an isotherm. In contrast, the cells in the $\mathrm{Al}-\mathrm{Cu}$ alloys were observed to cluster in the center, and the macroscopic tip front showed significant curvature.

\section{B. Segregation Profiles}

The curvature of the interface in the $\mathrm{Al}-\mathrm{Cu}$ system indicates a variation in the interface composition along the radial 


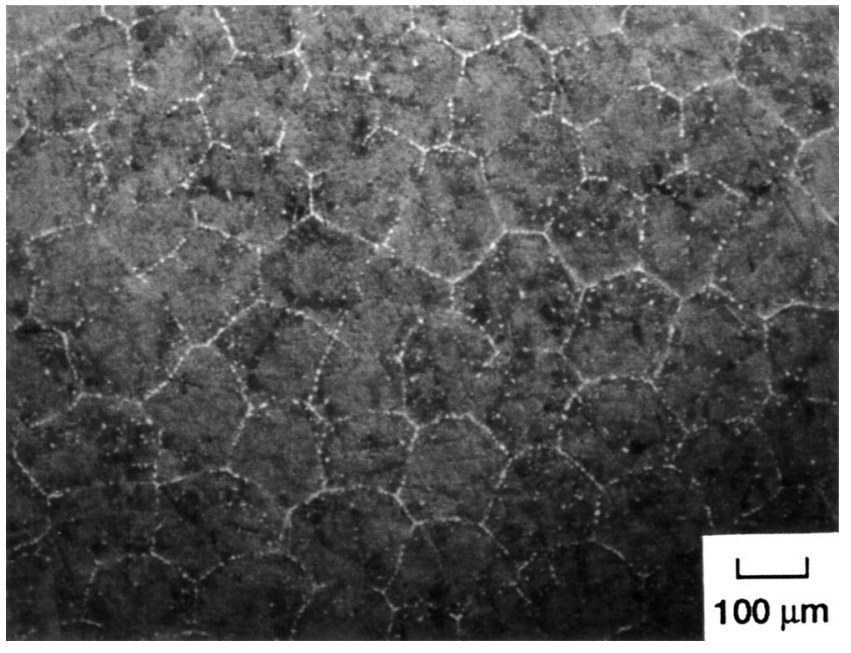

Fig. 2-A transverse microstructure of directionally solidified $\mathrm{Pb}-10 \mathrm{wt}$ pet $\mathrm{Sn}$ alloy at $V=2.5 \mu \mathrm{m} / \mathrm{s}$ and $G=11.0 \mathrm{~K} / \mathrm{mm}$.

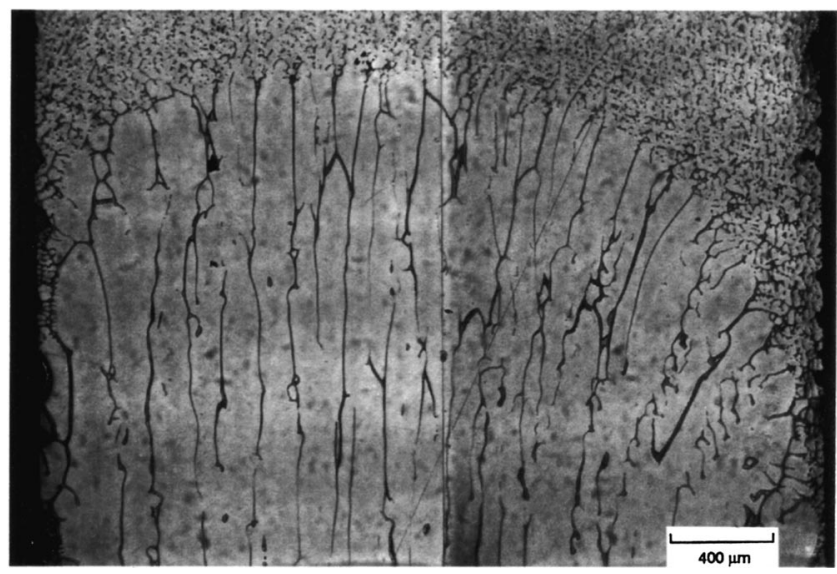

(a)

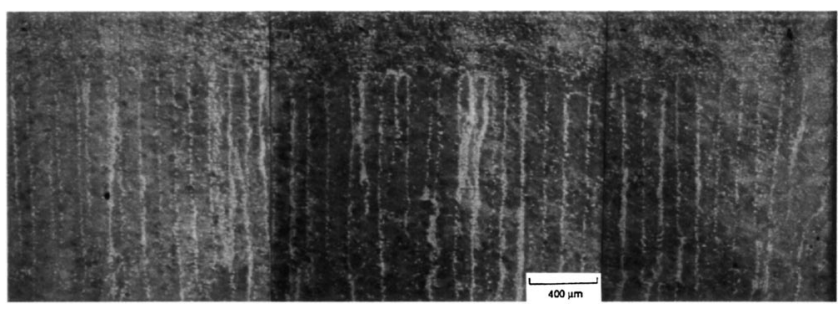

(b)

Fig. 3-Longitudinal cross sections of directionally solidified alloys: (a) Al-4.1 wt pet $\mathrm{Cu}, V_{P}=5.5 \mu \mathrm{m} / \mathrm{s}, G=14.0 \mathrm{~K} / \mathrm{mm}$. (b) $\mathrm{Pb}-10$ wt pet $\mathrm{Sn}$ alloy, $V=2.0 \mu \mathrm{m} / \mathrm{s}, G=11.0 \mathrm{~K} / \mathrm{mm}$, and Al-4.1 Cu wt pet alloy, $V=$ $\mu \mathrm{m} / \mathrm{s}$, and $G=14.0 \mathrm{~K} / \mathrm{mm}$. The macroscopic interface is almost flat for the $\mathrm{Pb}-\mathrm{Sn}$ alloy, whereas a significant curvature is observed in the Al$\mathrm{Cu}$ alloy.

direction. Consequently, two sets of measurements were carried out to examine the axial segregation in the two systems and the variation in composition and spacing along the radial direction. The measured axial-composition profiles in both the $\mathrm{Al}-\mathrm{Cu}$ and $\mathrm{Pb}-\mathrm{Sn}$ systems are shown in Figure 4. While the macrosegregation is almost insignificant in the former system, it is large in the latter. This is due to disparate levels of mixing in the two systems, as will be discussed in Section III-B.

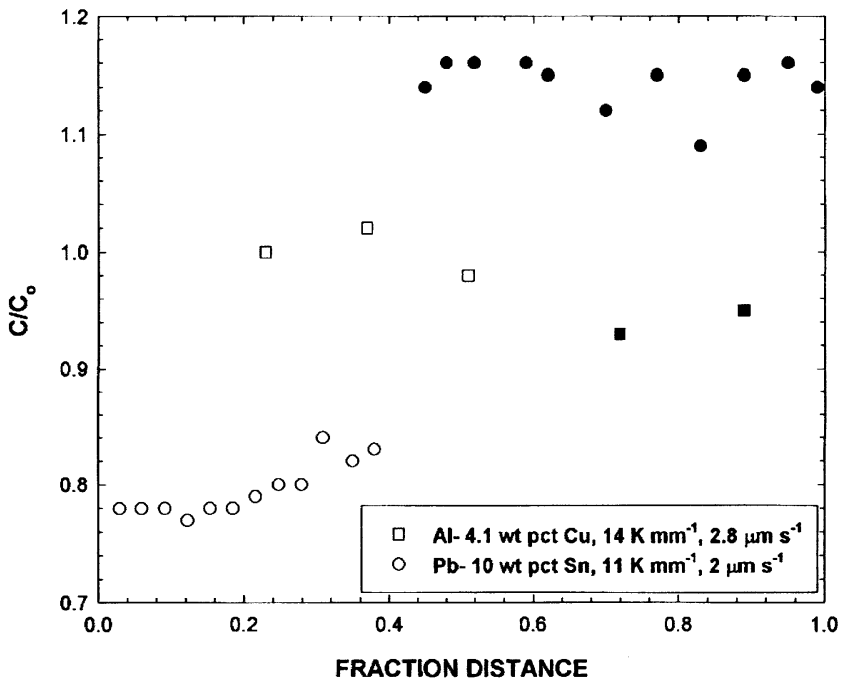

Fig. 4-Axial segregation profiles in the Al-4.1 wt pct $\mathrm{Cu}$ and $\mathrm{Pb}-10 \mathrm{wt}$ pct $\mathrm{Sn}$ systems. The Al-Cu system shows no significant macrosegregation, while $\mathrm{Pb}$-Sn shows large macrosegregation. Open points are for the solid, and filled points are for the quenched liquid.

Wall

Center

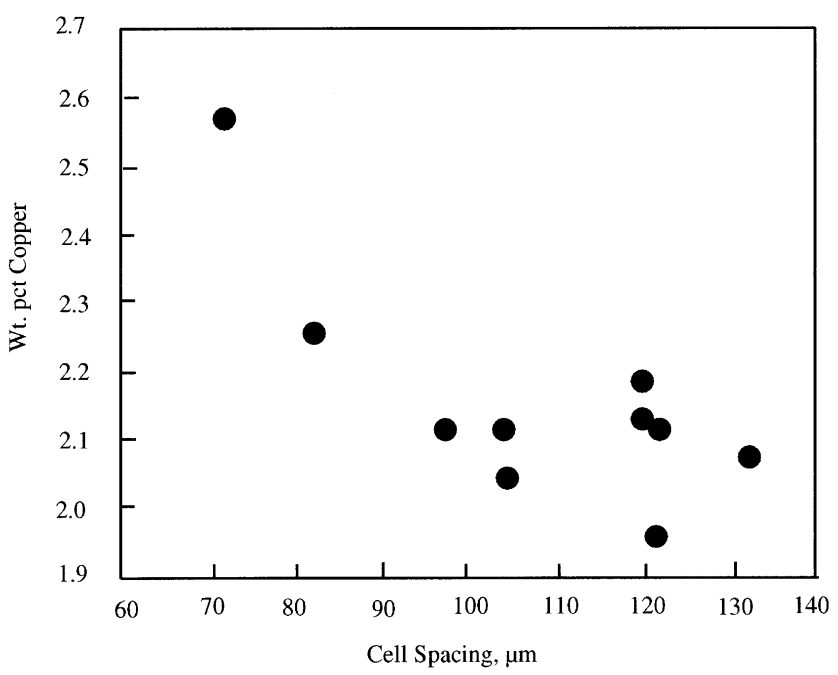

Fig. 5-The variation of primary spacing with composition at the center of cells or dendrite for a microstructure that exhibits the steepling effect. Al-4.0 wt pet alloy, directionally solidified at $1.83 \mu \mathrm{m} / \mathrm{s}$ at $G=14.0 \mathrm{~K} / \mathrm{mm}$.

The presence of curvature of the solidification front gives rise to varying thermal and solute conditions at different cell or dendrite tips in an array. Because of the lateral flow of solute due to convection, the composition in the liquid near the interface increases from the center to the sidewall. This variation in composition would be accompanied by the change in concentration gradients at the tips and give rise to a spacing disorder. In order to examine the effect of radial-composition variations, the average primary spacing is measured at different locations along the radial direction. Also, the composition in the solid at the cell or dendrite tip is measured for different cells/dendrites in an array. A variation in primary spacing as a function of tip composition in the solid is observed, as shown in Figure 5. The variation is small in the center region, but the spacing increases sharply 


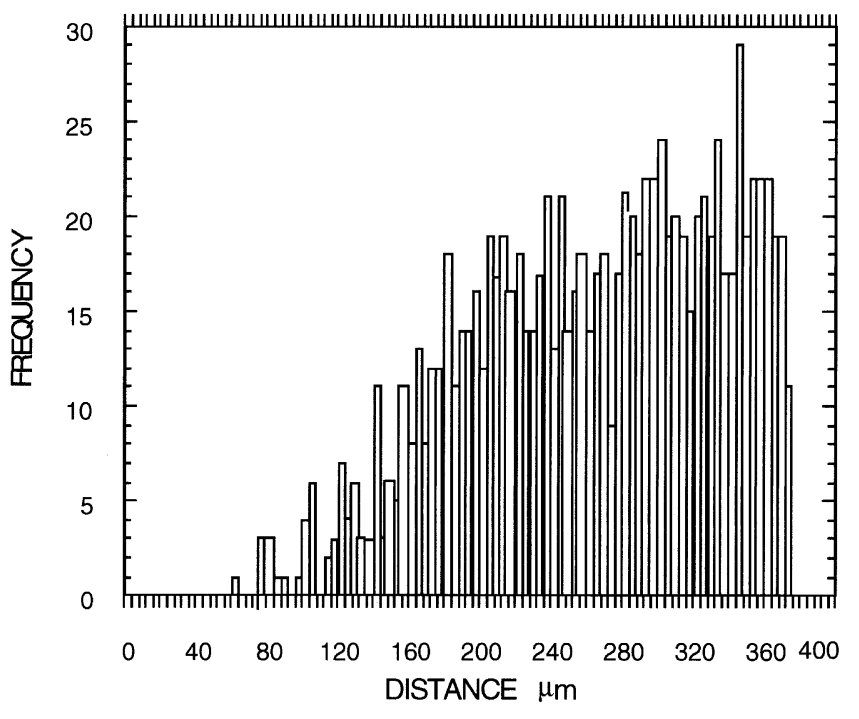

Fig. 6-A representative histogram of spacing between cells (or dendrites) including the nearest neighbor and higher order spacing for directionally solidified Al-4.1 wt pet directionally solidified at $V=11.0 \mu \mathrm{m} / \mathrm{s}$.

near the wall region. The variation in spacing is correlated with the tip composition, rather than distance, to clearly establish the effect of local composition variations on the primary spacing. In the very vicinity of the wall, the composition profile could alter due to the wall effect and cause a change in primary spacing. However, the extent of the wall effect is expected to be very small, and no such wall effect is seen in our results in the $\mathrm{Pb}-\mathrm{Sn}$ system or in the microgravity experimental result in the Al-Cu system. ${ }^{[19]}$ Consequently, the disorder in primary spacing, observed in our experiments in the $\mathrm{Al}-\mathrm{Cu}$ system, appears to be due to the radial variation in the solute profile caused by convection, and we shall establish this effect of convection, in this article, through the application of a numerical model.

\section{Primary-Spacing Analysis}

The average primary spacing is generally determined from a transverse cross section by counting the number of cells or dendrites present in a circular region of a fixed diameter. Then, by assuming a hexagonal, square, or random distribution, the average primary-spacing value is calculated. ${ }^{[10,34,35]}$ The value of the primary spacing is, thus, influenced by the distribution assumed for calculations. Note that the real distribution does not show an equal number of neighboring cells or dendrites, so that such a method cannot characterize disorder in primary spacings.

Another common method in the literature for characterizing the primary spacing is to measure a large number of nearest-neighbor distances and then obtain the average value. We have determined the distribution of spacings between two points from the array of points that represent the center of mass of each cell. In principle, one should obtain sharp peaks that correspond to the first, second, third, etc., nearestneighbor spacing. From this distribution, the nearest-neighbor spacing could be determined. The experimental data on the distribution of the distances between the points is shown in Figure 6. Although the peaks for the first and second nearest neighbors can be seen, the distribution is not sharp,

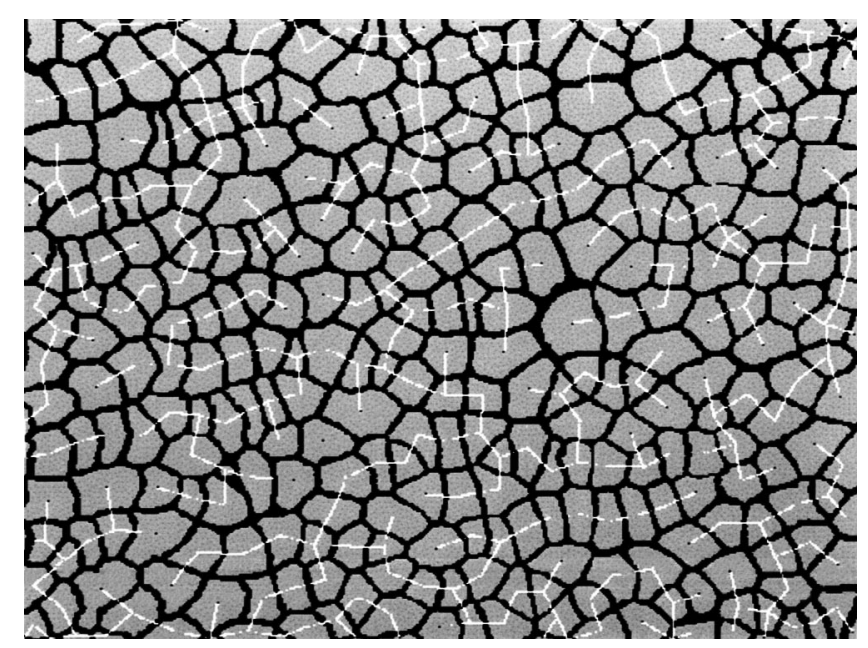

Fig. 7-A typical binary image of a transverse cross section of a directionally solidified alloy. The construction of a minimal spanning tree is shown for a cellular array in Al-4.1 wt pet $\mathrm{Cu}$ alloy, directionally solidified at 5.5 $\mu \mathrm{m} / \mathrm{s}$ and $G=14.0 \mathrm{~K} / \mathrm{mm}$

which indicates that some disorder is present in the spatial arrangement of dendrites. One of the problems in this method is to accurately identify the nearest neighbors when the distribution has a significant disorder. Since our aim is to characterize the disorder, we shall analyze primary-spacing data by using two different methods that have been developed to accurately determine the disorder. These methods are (1) the weighted Wigner-Seitz (W-S) method or the Voronoi tessellation method ${ }^{[36,37]}$ and (2) the minimal spanning-tree (MST) method. ${ }^{[36-39]}$

In the W-S and MST methods, the array is first characterized by a set of points. To obtain a set of points, the transverse microstructures, shown in Figures 1 and 2, were first digitized and photo enhanced to obtain well-defined cell or dendrite boundaries. A binary image was then produced, in which the cell/dendrite interiors were white and the cell or dendrite boundaries were black, as shown in Figure 7. The first step in the image analysis was to determine the coordinates of the centers of each cell/dendrite and the surface area of the cell. The center of the cell or dendrite was taken as the center of mass of all the pixels in the cell or dendrite. Once the coordinates of the centers were determined, a twodimensional spatial arrangement of points was obtained, which was then analyzed by using the weighted W-S method and the MST method.

The most accurate method to quantitatively analyze the disorder in primary-spacing data is to characterize the number of nearest neighbors for each cell or dendrite and then to look at the statistical distribution of the number of neighbors. This is achieved by the weighted W-S method. ${ }^{[36,37]}$ In the $\mathrm{W}-\mathrm{S}$ method, a perpendicular line is drawn between the two neighboring points, and the inner envelope of all lines with neighbors for a given point gives a polygonal shape. In the weighted W-S method, the line between the two neighboring points is drawn such that the ratio of the distances to the two points from any location on the line is equal to the ratio of the square root of the surface area of the cell or dendrite representing the point. ${ }^{[38]}$ By this method, one obtains an array of polygons, each of which contains an original cell or dendrite. The polygons will be hexagonal for a perfect hexagonal array, whereas polygons with more or less than 


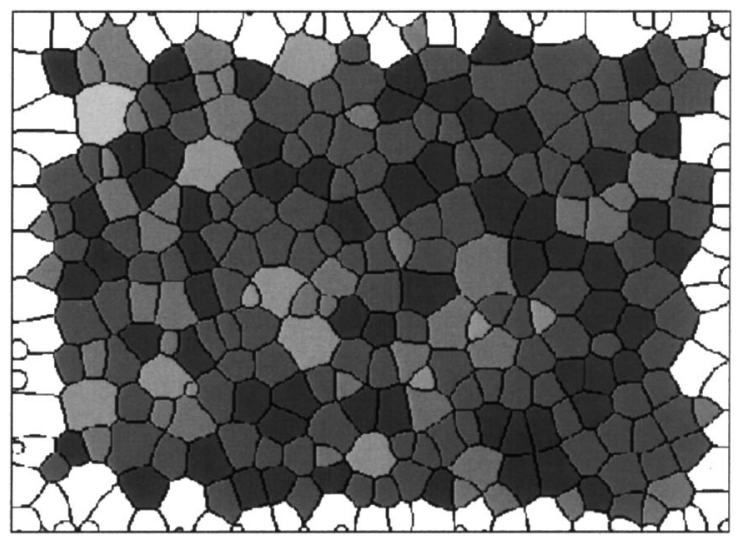

(a)

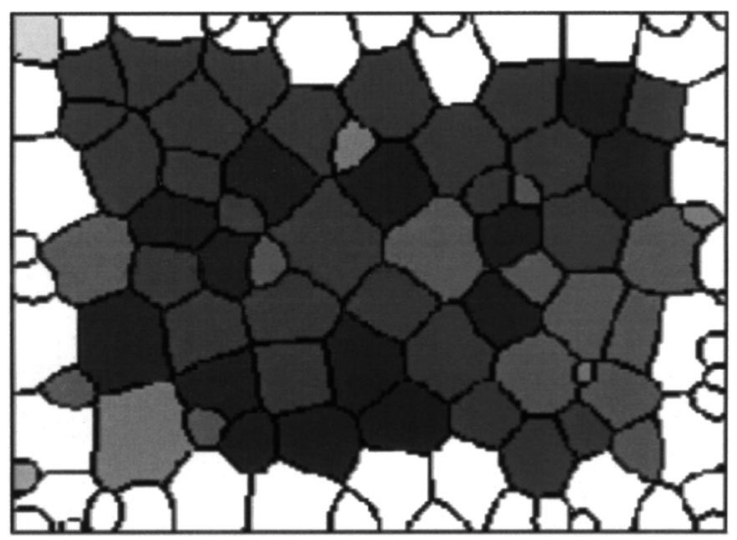

(b)

Fig. 8-Representative examples of the modified W-S construction showing the nearest neighbor cells and dendrites in $\mathrm{Al}-10$ wt pct $\mathrm{Cu}$ system. Different gray levels show the presence of 5 to 7 and 4 to 8 sides of polygons. The results are for velocities: (a) $5.5 \mu \mathrm{m} / \mathrm{s}$ and (b) $44.0 \mu \mathrm{m} / \mathrm{s}$.

six sides will be present when any disorder is present. The weighted W-S construction gives us additional information on the number of nearest neighbors, the area of each cell, and the number and length of each side of the cell.

The experimental results for the Al-Cu samples are shown in Figure 8. As discussed by Smith, ${ }^{[40]}$ the space-filling constraint requires that any disorder with a polygon containing less than six sides will be accompanied by a polygon with more than six sides. Thus, we have shown the pairs of five-seven, four-eight, and three-nine-sided polygons by the variation in gray levels in Figure 8. The frequencies of polygons of different sides for the $\mathrm{Pb}-\mathrm{Sn}$ and $\mathrm{Al}-\mathrm{Cu}$ alloys are shown in Figures 9 and 10. There does not appear to be a significant difference between the distributions of cells and dendrites, either for $\mathrm{Pb}-\mathrm{Sn}$ or $\mathrm{Al}-\mathrm{Cu}$ alloys. Note that a perfect hexagonal arrangement would give only six-sided cells. A wider distribution showing the presence of threenine-sided cells indicates that a significant randomness is present in the arrangement of cells or dendrites. The average value of the $\mathrm{W}-\mathrm{S}$ diameter, which is proportional to the primary spacing, is shown in Figure 11 as a function of velocity. Since the average spacing is proportional to the average $\mathrm{W}-\mathrm{S}$ diameter, the increase in spacing with velocity is consistent with the spacing variation observed in the celldendrite transition region. ${ }^{[6,9-16]}$

The primary-spacing distribution was found to be more random in the $\mathrm{Al}-\mathrm{Cu}$ system than in the $\mathrm{Pb}-\mathrm{Sn}$ system. The mean number of cell sides and the spread about the mean is more disordered in the $\mathrm{Al}-\mathrm{Cu}$ system than in the $\mathrm{Pb}-\mathrm{Sn}$ system. The most probable number of sides is six for $\mathrm{Pb}$ $\mathrm{Sn}$ alloys, whereas it is close to five for $\mathrm{Al}-\mathrm{Cu}$ alloys. The aforementioned results seem to be counter-intuitive, since the highly convective $\mathrm{Pb}$-Sn system shows lower disorder than the weakly convective Al-Cu system.

The disorder in the spatial arrangement of cells and dendrites can also be examined by using the MST method. ${ }^{[38]}$ In this method, the MST is constructed by selecting any point in the array and then connecting it to the neighboring point that is closest to the selected point, and this process is repeated until all points are connected. Thus, the MST is a connected graph which contains all the cell centers and in which the sum of edge lengths is minimum. A histogram of the edge lengths is plotted and characterized by the mean value $(m)$ and the standard deviation $(\sigma)$. The value of $(m, \sigma)$ obtained from the experimental results is then compared with the reference curves. Dussert et al. ${ }^{[38]}$ obtained the reference curves by taking a perfect hexagonal or square array of points and then introducing a known Gaussian noise on the array of points. They determined the corresponding $(m, \sigma)$ values as a function of noise. These reference curves as shown in Figure 12 for an initially square and a hexagonal array of points. Note that a random distribution is predicted when $m=0.65$ and $\sigma=0.30$, since the disordered values of square and hexagonal arrangements meet at that point.

The $(m, \sigma)$ pairs for the points representing a cellular or a dendritic array observed experimentally are calculated for $\mathrm{Al}-\mathrm{Cu}$ and $\mathrm{Pb}-\mathrm{Sn}$ systems. The results are shown in Figure 12. Two different regions in one $\mathrm{Pb}-\mathrm{Sn}$ alloy were analyzed to test the reproducibility of results for a given growth condition. The $(m, \sigma)$ values for a directionally solidified $\mathrm{Pb}-30$ wt pet Tl alloy $(G=45 \mathrm{~K} / \mathrm{cm}$ and $V=3.06 \mu \mathrm{m} / \mathrm{s})$, reported by Billia et al. ${ }^{[36]}$ are also shown for comparison. Our experimental results show that the arrangements of cells and dendrites in the $\mathrm{Al}-\mathrm{Cu}$ and $\mathrm{Pb}-\mathrm{Sn}$ systems are significantly disordered, and a larger value of $\sigma$ is found for the Al-Cu system, which is consistent with the results obtained by the weighted W-S method.

In summary, experimental results show that a disorder in the array is present in both the $\mathrm{Al}-\mathrm{Cu}$ and the $\mathrm{Pb}-\mathrm{Sn}$ systems. Although the amount of convection is significant in the $\mathrm{Pb}$ Sn system, our results show that the arrays are predominantly hexagonal, as seen in the histograms of the number of sides of the $\mathrm{W}-\mathrm{S}$ polyhedra. For all velocities, the peak corresponds to a six-sided polyhedron. Also, the MST results show the mean value to be 89 pct of the perfect hexagonal array, and the standard deviation is found to be 0.14 . In contrast, the distribution of cells and dendrites in the Al-Cu system was found to be significantly more random. The W-S construction showed a peak at either five or six sides, and significantly wider distributions of number of sides were observed, e.g., the number of sides varies from three to nine. Also, the MST results, shown in Figure 12, indicated a larger disorder from the perfect hexagonal array, with a standard deviation of 0.19 . Since convection is stronger in the $\mathrm{Pb}$ $\mathrm{Sn}$ system compared to that in the $\mathrm{Al}-\mathrm{Cu}$ system, array disorder is not directly related to the intensity of convection. We shall, thus, use a numerical model of convection to 


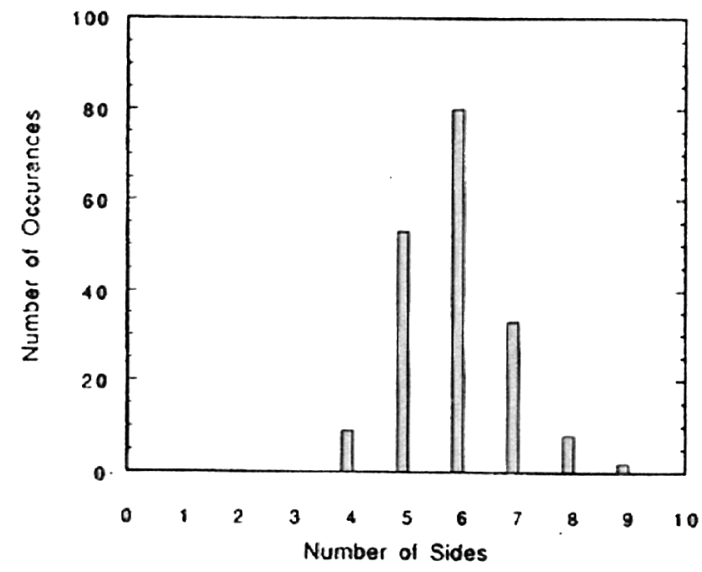

(a)

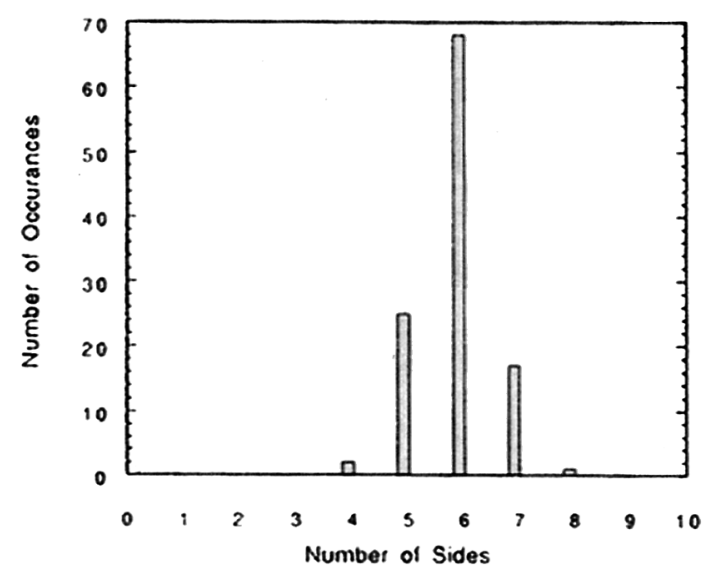

(c)

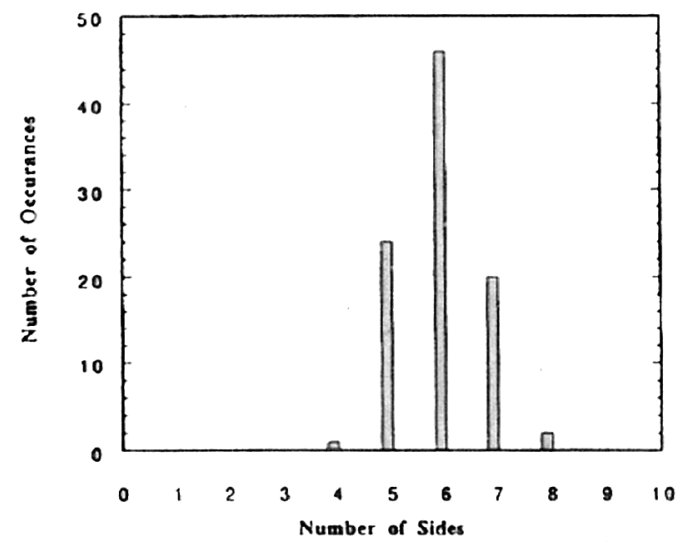

(b)

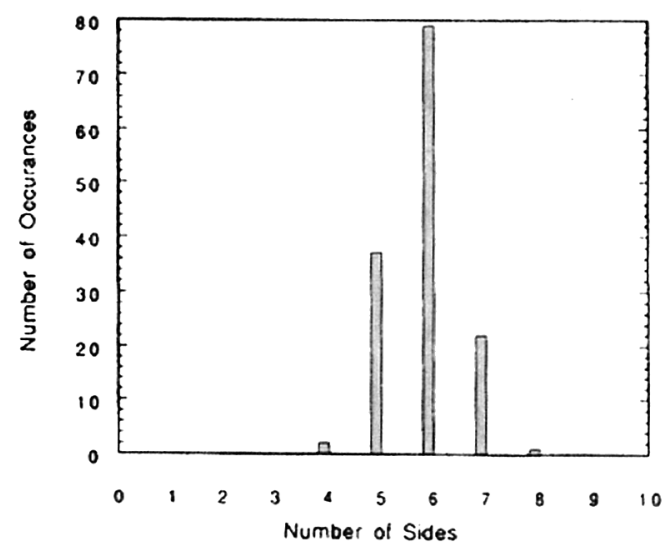

(d)

Fig. 9-Histogram of nearest neighbor of polygons in the W-S construction for Pb-Sn alloys directionally solidified at velocities: (a) $2.5 \mu \mathrm{m} / \mathrm{s},(b) 3.5$ $\mu \mathrm{m} / \mathrm{s},(c) 4.0 \mu \mathrm{m} / \mathrm{s}$, and (d) $8.0 \mu \mathrm{m} / \mathrm{s}$.

better understand the relations among flow, segregation, and primary spacing.

\section{NUMERICAL MODELING}

The numerical simulations described here solve a complete two-dimensional model for heat transfer, melt convection, and solute transport in a prototype of the vertical Bridgman crystal-growth system. The aim of these calculations is to characterize the different nature of fluid that occurs in the $\mathrm{Al}-\mathrm{Cu}$ and $\mathrm{Pb}-\mathrm{Sn}$ systems, in which the solute is heavier and lighter than the solvent, respectively. The complex transport problem is solved by the finite-difference method using alternate-direction implicit integration. ${ }^{[38,39]}$ The model is briefly described as follows, and the details of mathematical aspects, including appropriate boundary conditions, are given elsewhere. ${ }^{[17,31,32]}$

\section{A. Model}

The simulations have been carried out for the Bridgman system, shown schematically in Figure 13. The model includes heat transfer in the melt and a crystal contained in a two-dimensional ampoule which is surrounded by a moving thermal assembly consisting of hot and cold zones separated by an insulated region. The field variables, velocity, pressure, temperature, and solute composition are described in a dimensionless coordinate reference frame $(x, y)$ that is fixed with the lower end of the sample, as shown in Figure 13. Variables are put in dimensionless form by scaling the coordinates $(x, y)$ and lengths with the inner width of the ampoule $(d)$, the time $(t)$ with the scale for heat diffusion $\left(d^{2} / \alpha_{1}\right)$, and the velocity $(\mathbf{u}(x, y, t))$ with the characteristic velocity of heat diffusion $\left(\alpha_{1} / d\right)$, where $\alpha_{1}$ is the thermal diffusivity of the melt. The dimensionless composition and temperature fields are defined as

$$
\begin{gathered}
c=\frac{C-C_{0}}{C_{0}} \\
\theta=\frac{T-T_{C}}{T_{H}-T_{C}}
\end{gathered}
$$

where $T_{H}$ and $T_{C}$ are the characteristic temperatures of the isothermal hot and cold zones of the furnaces. The twodimensional time-dependent equations describing convection and heat solute transport are 


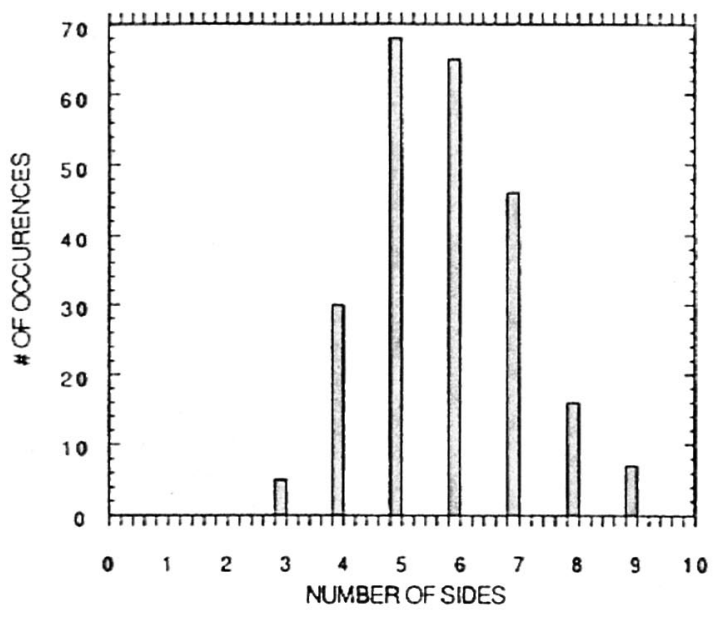

(a)

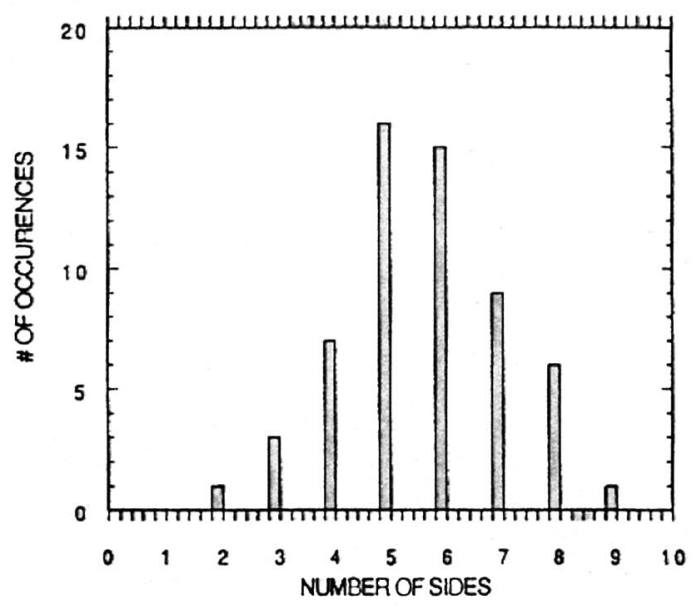

(c)

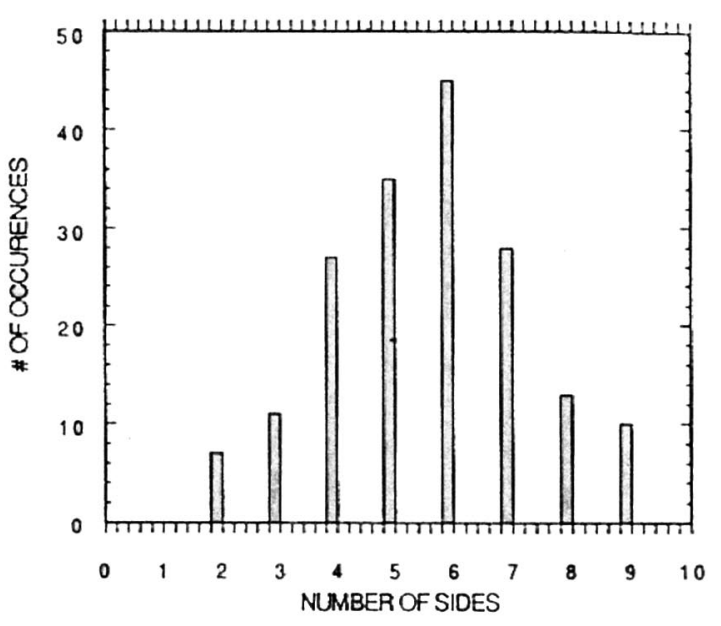

(b)

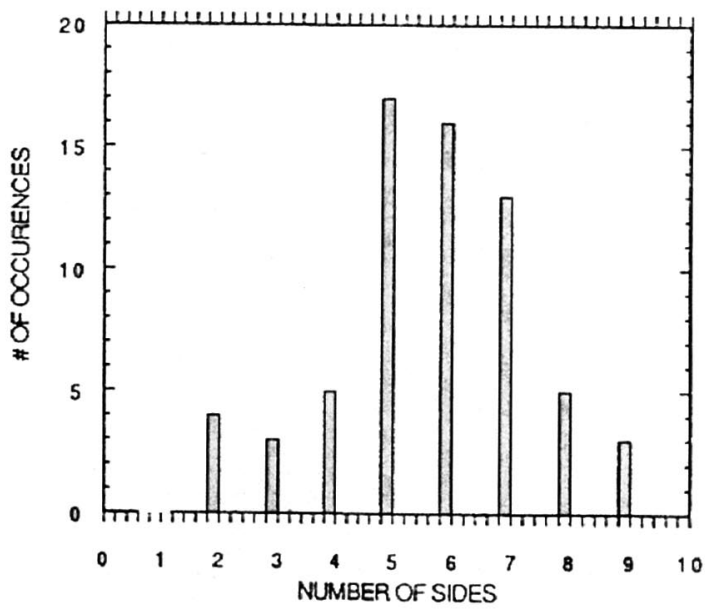

(d)

Fig. 10-Histogram of nearest neighbor of polygons in the W-S construction for Al-Cu alloys directionally solidified at velocities: $(a) 5.5 \mu \mathrm{m},(b) 11.0$ $\mu \mathrm{m},(c) 22.0 \mu \mathrm{m}$, and $(d) 44.0 \mu \mathrm{m} / \mathrm{s}$.

$$
\begin{gathered}
\frac{\partial \mathbf{u}}{\partial t}+\left(\mathbf{u}-\mathbf{v}_{p}\right) \cdot \nabla \mathbf{u}=-\nabla p+\nabla^{2} \mathbf{u} \\
+\frac{1}{\operatorname{Pr}}\left(\operatorname{Ra}_{s} c-\operatorname{Ra}_{T}\left(\theta-\theta_{0}\right)\right) \\
\nabla \cdot \mathbf{u}=0 \\
\frac{\partial c}{\partial t}+\left(\mathbf{u}-\mathbf{v}_{p}\right) \cdot \nabla c=\frac{1}{\operatorname{Le}} \nabla^{2} c \\
\frac{\partial \theta}{\partial t}+\left(\mathbf{u}-\mathbf{v}_{\mathbf{p}}\right) \cdot \nabla \theta=\nabla^{2} \theta
\end{gathered}
$$

where $\theta_{0}$ is a reference temperature. The dimensionless groups that appear in the equations are defined in Table II. The heat-transport equations in the solidified crystal and ampoule are

$$
\frac{\partial \theta}{\partial t}+\mathbf{v}_{p} \cdot \nabla \theta=\frac{\alpha_{s}}{\alpha_{l}} \nabla^{2} \theta
$$

$$
\frac{\partial \theta}{\partial t}+\mathbf{v}_{p} \cdot \nabla \theta=\frac{\alpha_{a}}{\alpha_{l}} \nabla^{2} \theta
$$

where $\alpha_{s}$ and $\alpha_{a}$ are the thermal of diffusivities of the solid crystal and the ampoule, respectively.

The boundary conditions on the velocity field on the ampoule and at the melt/crystal interface specify that there is no slip relative to the solid surfaces. Along the ampoule inner wall, the continuity of the heat flux and the temperature between the melt, crystal, and ampoule are specified. The vertical ampoule walls are impervious to mass flux. The temperatures at the bottom and the top surfaces are prescribed according to measured experimental data. Isothermal temperatures equal to those of the hot and cold zones are possible to prescribe at these boundaries. But, this needs careful selection of the length of the computational domain. Using smaller computational domains than those required for the temperature in the liquid and solid to gradually reach the isothermal furnace temperatures and fixing the tempera- 


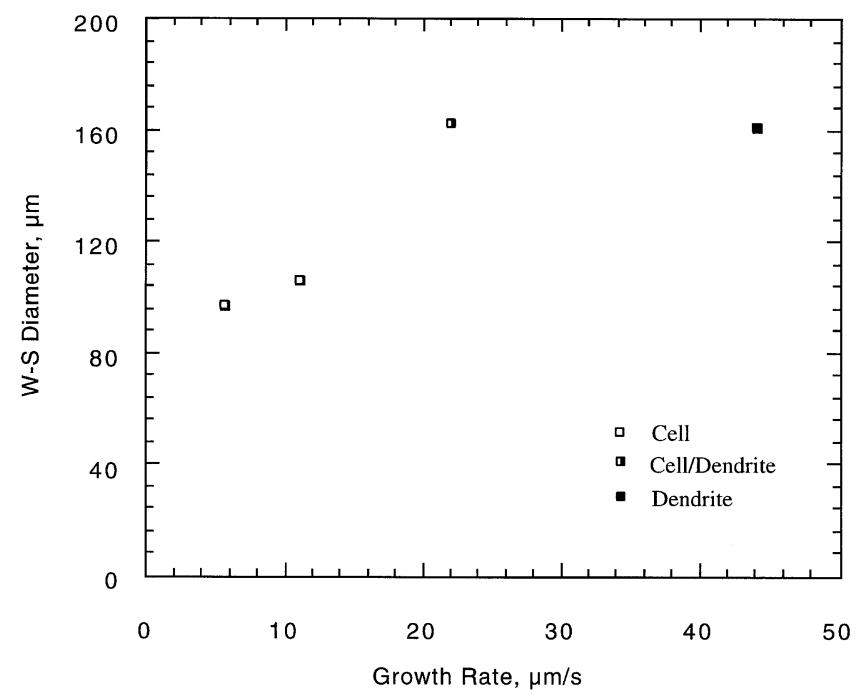

Fig. 11-The variation in the average diameter of $\mathrm{W}-\mathrm{S}$ cells as a function of velocity in the Al-Cu system.

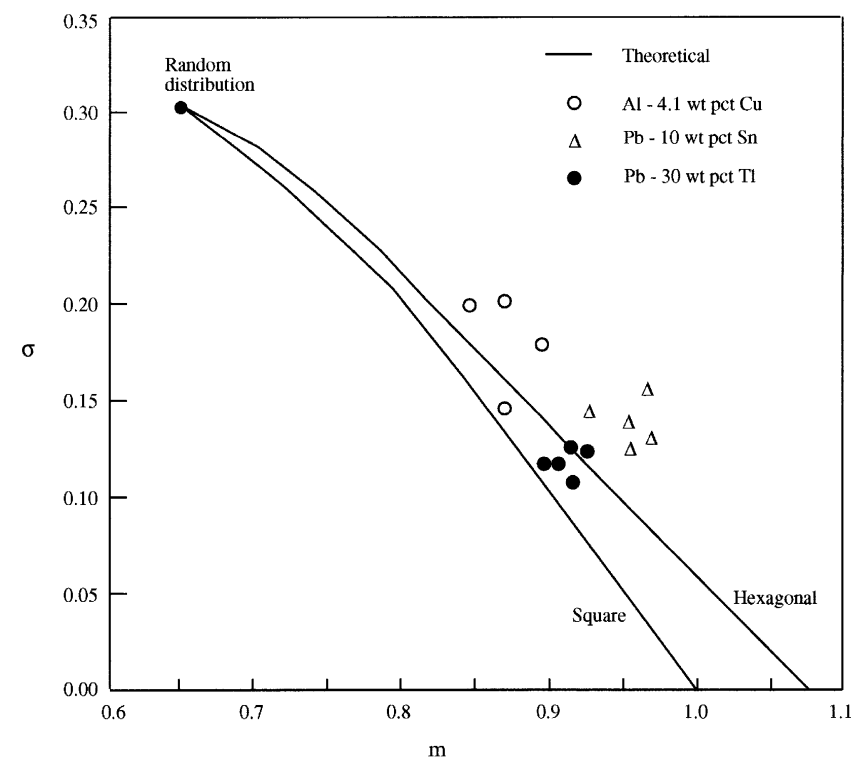

Fig. 12-The $(m, \sigma)$ diagram for the distribution of cellular and dendritic arrays in the $\mathrm{Pb}-10$ wt pet $\mathrm{Sn}$ (squares), Al-4.1 wt pct $\mathrm{Cu}$ (circles), and $\mathrm{Pb}-30$ wt pet $\mathrm{Tl}$ (triangles) ${ }^{[8]}$ alloys. The filled symbols correspond to the dendrites and the open symbols to the cells. Theoretical lines for hexagonal and square array as a function of disorder are also shown for comparison.

tures at the furnace temperatures can lead to unrealistically high axial and radial temperature gradients..$^{[17,31,32]}$ Proper care is necessary for physically realistic simulation while describing the thermal boundary conditions and fixing the lengths of the computational domain in the absence of experimental data. ${ }^{[17,31,32]}$ The solid-liquid interface is continuously rejecting solute, and the boundary condition is

$$
\frac{\partial c}{\partial x}=-v_{P} \operatorname{Le}(1+c)(1-k)
$$

in which $k$ is the partition coefficient.

The outer surfaces of the ampoule are assumed to exchange heat with the surrounding furnace according to Newton's law of cooling:

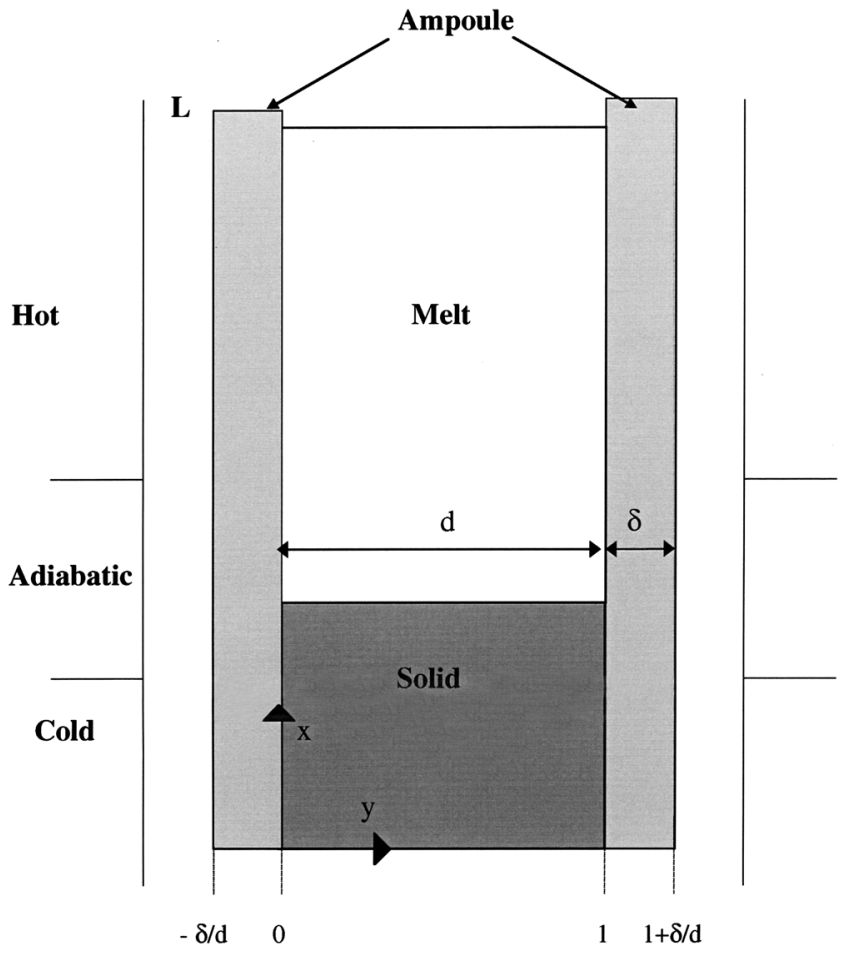

Fig. 13-A sketch of the Bridgman system with parameters used in the computational model.

$$
\begin{array}{r}
\frac{f \theta_{a}}{f y}=-\mathrm{Bi}_{c}\left(\theta_{x}-\theta_{a}\right) \quad \text { in the cold zone } \\
\frac{f \theta_{a}}{f y}=-\mathrm{Bi}_{a}\left(\theta_{x}-\theta_{a}\right) \quad \text { in the adiabatic zone } \\
\frac{f \theta_{a}}{f y}=-\mathrm{Bi}_{h}\left(\theta_{x}-\theta_{a}\right) \quad \text { in the hot zone }
\end{array}
$$

where $\mathrm{Bi}_{h}$ and $\mathrm{Bi}_{c}$ and $\mathrm{Bi}_{a}$ are the nondimensional heattransfer coefficients (or, the Biot numbers) in the hot, cold, and adiabatic zones, respectively; and $\theta_{\infty}$ is the furnacetemperature distribution obtained by direct measurement. ${ }^{[17]}$ The proper choice of the heat-transfer coefficients is made through regression analysis of computed axial and radial temperature profiles with measured experimental data. The set of partial differential equations is solved using secondorder finite-difference schemes, with alternate-direction implicit integration. ${ }^{[41,42]}$ Local grid refinement is used for the concentration field in the $\mathrm{Pb}-\mathrm{Sn}$ system to resolve the thin boundary layers adjacent to the solid walls.

\section{B. Numerical Results}

Only the salient results germane to the effect of convection in axial and lateral segregation of solute and its effect on the disorder of cellular spacings are presented in this section. The details of the structure and nature of flow and thermal field in response to variations of design and processing parameters will be described in a separate article. ${ }^{[32]}$

The convection-induced disparate disorder in the $\mathrm{Pb}-\mathrm{Sn}$ and $\mathrm{Al}-\mathrm{Cu}$ systems could be best examined by considering the lateral-composition profiles. The simulated lateral-composition profiles at the advancing solid-liquid interface during growth are evaluated at a low velocity of $1.0 \mu \mathrm{m} / \mathrm{s}$, 
Table II. Dimensional Groups and Their Characteristic Values Used in Simulation

\begin{tabular}{|c|c|c|c|c|}
\hline Group & Symbol & Definition & \multicolumn{2}{|c|}{ Values } \\
\hline Thermal Rayleigh number & $\mathrm{Ra}_{T}$ & $\underline{g \beta_{T}\left(T_{h}-T_{C}\right) d^{3}}$ & $\begin{array}{l}\mathrm{Al}-\mathrm{Cu} \\
10,000\end{array}$ & $\begin{array}{l}\mathrm{Pb}-\mathrm{Sn} \\
7000\end{array}$ \\
\hline Solutal Rayleigh number & $\mathrm{Ra}_{s}$ & $\begin{array}{c}\alpha_{l} \nu \\
\frac{g \beta_{s} C_{0} d^{3}}{\alpha_{l} \nu}\end{array}$ & 4000 & $-70,000$ \\
\hline Prandtl number & $\operatorname{Pr}$ & $\nu / \alpha_{1}$ & 0.013 & 0.009 \\
\hline
\end{tabular}

where the convection effects will be large, and the results for both the systems are plotted in Figure 14 for different times. The numbers immediately above the curves indicate the time in seconds from the start of solidification. The low-intensity convection in the Al-Cu system causes a large variation in solute concentration across the interface. The composition varies smoothly across the entire cross section without showing any boundary-layer-type characteristic at the sidewalls. This suggests that the microstructural characteristic must be different for different points on the interface, and a significant disorder in spacing may result, since the primary spacing depends on the composition and the composition gradient at the tip of the cell or dendrite. ${ }^{[3,4,13]}$ In contrast, the solute concentration in the $\mathrm{Pb}-\mathrm{Sn}$ system is significantly homogeneous over most of the cross section of the interface. Hence, in this region, the microstructural characteristic should be relatively uniform for different points, and this should lead to lower disorder than that in the $\mathrm{Al}-\mathrm{Cu}$ system. A thin boundary-layer-type region is observed near the sidewalls for the $\mathrm{Pb}-\mathrm{Sn}$ system, where the concentration sharply rises. This is a consequence of intense convection in the $\mathrm{Pb}-\mathrm{Sn}$ melt, which causes more uniform mixing. Using quasi-steady-state models, earlier investigators observed that for a given furnace-ampoule combination, the amount of compositional nonuniformity (or radial segregation) was a nonlinear function of the Rayleigh number. ${ }^{[27-29,43]}$ The most important result of these calculations has been to demonstrate that between the diffusion-controlled and complete mixing limits for solute transport in the melt lies a region of poor mixing, which leads to large lateral segregation of solute along the radial direction.

Besides the radial concentration variation, convection will also alter the axial concentration profiles. The flow in the Al-Cu system is found to be steady and weak due to the dampening effect of the solute field, and it leads to a solute transport that is almost diffusion-dominated along the axial length. This is illustrated in Figure 15. The axial concentration profiles in the melt are plotted in Figure 15(a) along the edge and the centerline. The concentration in the liquid at the interface did not reach the steady-state composition (23 pct) over the computation time. However, the asymptotic decay of the concentration to its initial value far downstream of the interface clearly suggests a diffusion-dominated transport. This conclusion is bolstered in the accompanying plot of axial solute-segregation profiles in the solid along the length of the solidified sample (Figure 15 (b)). The calculated curves along the edge and the centerline are compared to the one-dimensional analytical model by Tiller et al., ${ }^{[44]}$ and similar trends are

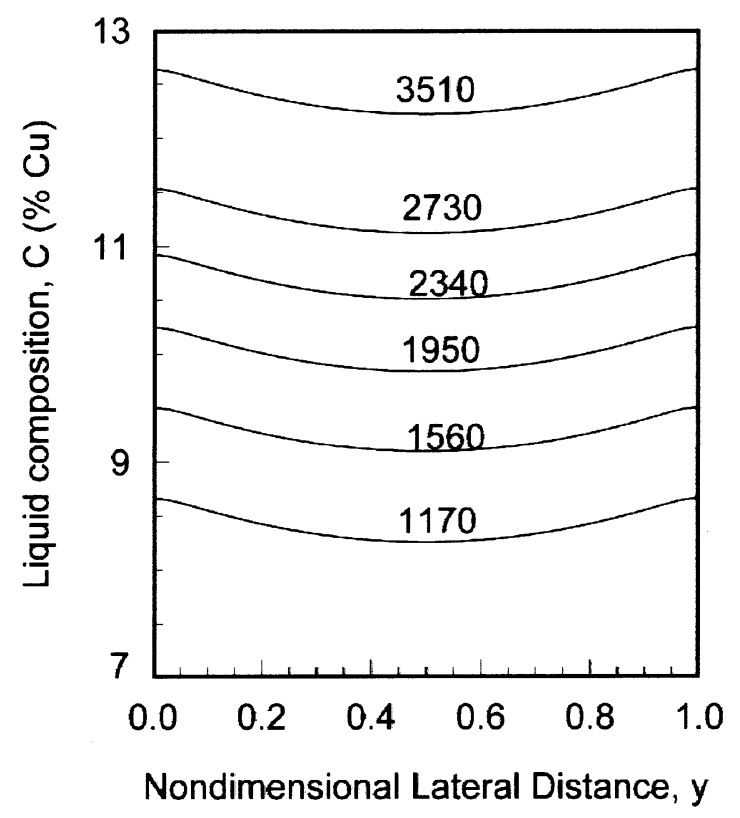

(a)

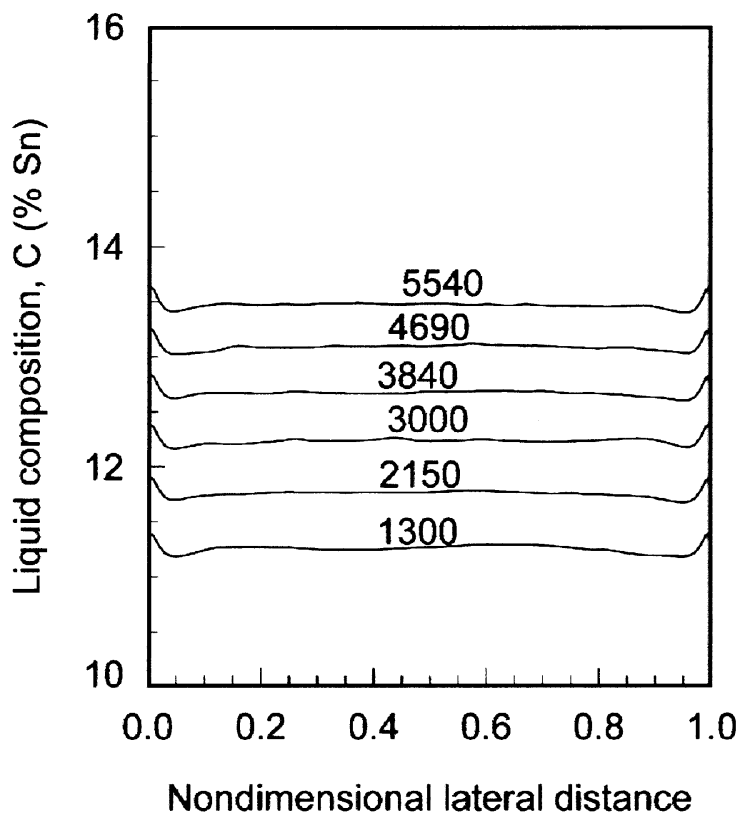

(b)

Fig. 14-Lateral interface composition profiles at different times (seconds) from the start of solidification at $V=1.0 \mu \mathrm{m} / \mathrm{s}$. (a) Al-4 pct $\mathrm{Cu}$ and $(b)$ $\mathrm{Pb}-10$ pct $\mathrm{Sn}$. The low intensity convection in the $\mathrm{Al}-\mathrm{Cu}$ system causes higher lateral segregation than in the $\mathrm{Pb}-\mathrm{Sn}$ system. 


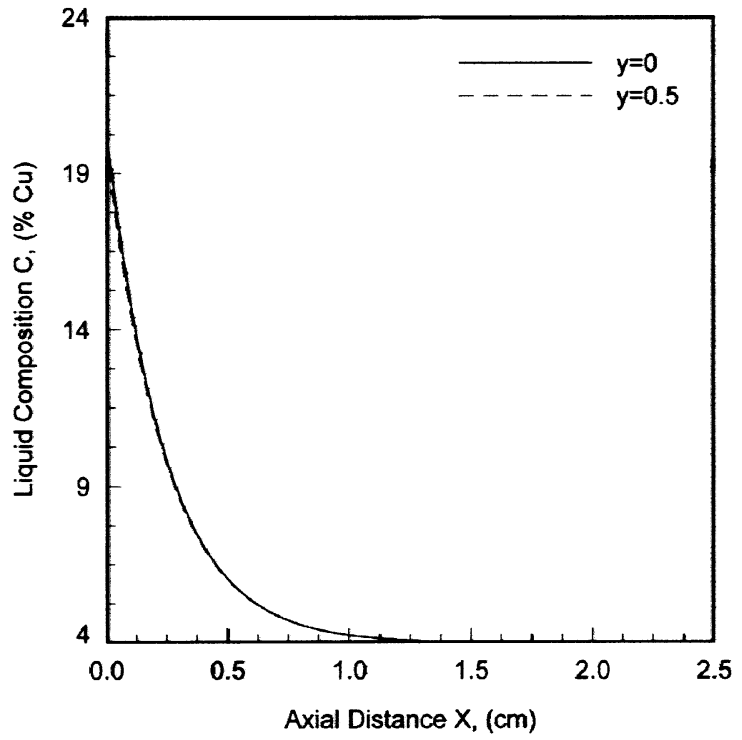

(a)

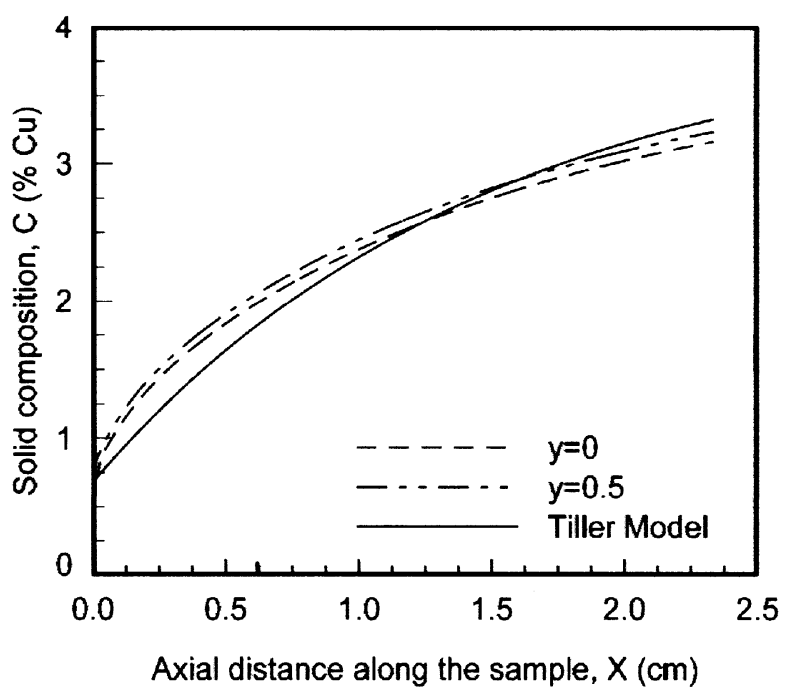

(b)

Fig. 15-Almost diffusion dominated axial solute profiles in Al-4 pct $\mathrm{Cu}$ system for $\mathrm{V}=1.0 \mu \mathrm{m} / \mathrm{s}$. (a) Solute profile in the liquid ahead of the interface. $(b)$ Axial solute profiles in the solid along the length of solidified sample. The axial profiles along the edge and the center of the sample are close to the diffusive model. ${ }^{[44]}$

observed. The axial concentration gradient at the side is slightly higher than that at the center. This low-intensity flow, however, is responsible for causing large lateral segregation, as observed in Figure 14. This large lateral segregation, along with a diffusion-type axial segregation, is consistent in terms of degrees of mixing caused by lateral temperature gradients and the solutal damping of the flow caused by the rejection of a heavier solute. Similar phenomena have been observed experimentally by Capper et al. ${ }^{[45]}$ for $\mathrm{HgCdTe}$ systems, which were later explained through numerical modeling. [28]

In the $\mathrm{Pb}-\mathrm{Sn}$ system, the flow is stronger and highly unsteady due to the rejection of lighter solute at the interface. This fluid motion leads to a convection-dominated solute transport along both the lateral and axial directions.

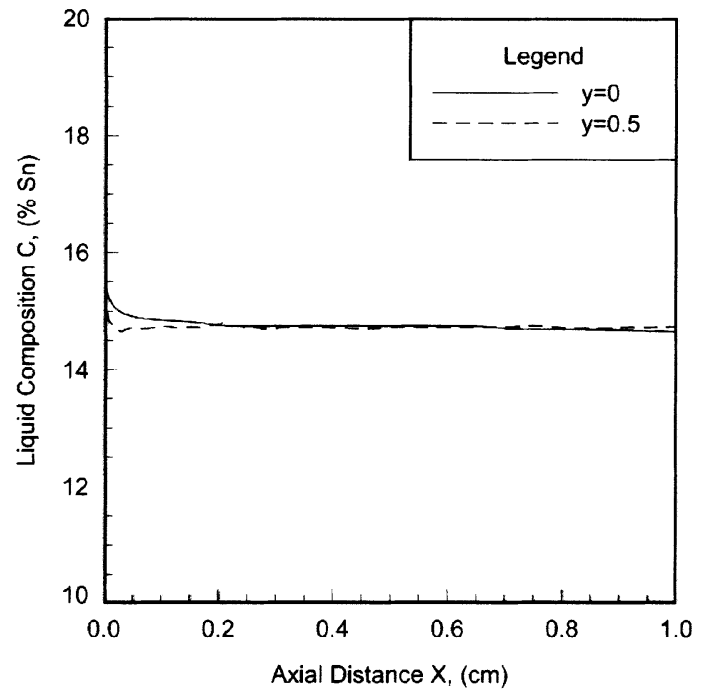

(a)

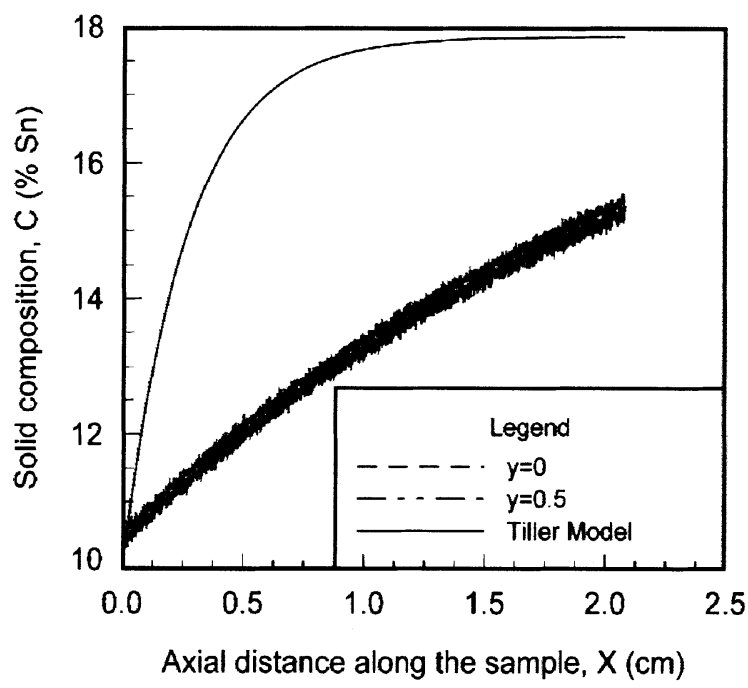

(b)

Fig. 16-Almost perfectly mixed axial solute profiles in the $\mathrm{Pb}-10$ pct $\mathrm{Sn}$ system. (a) Solute profile in the liquid ahead of the interface shows a thin boundary layer type characteristic outside of which the melt is almost perfectly mixed due to vigorous convection. The uniform melt composition, however, is much higher than the initial composition (10 pct). (b) Axial segregation profiles along the length of the solidified sample along the edge and the center. The actual profiles along the edge and the center of the sample deviate considerably from the results of the diffusive model. ${ }^{[44]}$

This is illustrated in Figures 16(a) and (b). The axial concentration profiles in the liquid melt are plotted in Figure 16(a) along the wall and the centerline. Except for a thin boundary-layer-type region adjacent to the interface, the melt composition is almost uniform over the entire length of the melt due to vigorous mixing in the melt. The calculated axial segregation profiles in the solidified sample are compared to the diffusion model ${ }^{[44]}$ in Figure 16(b). A highfrequency and small-amplitude fluctuation is observed due to the quasi-periodic fluid flow. The large departure of the calculated segregation profiles from the diffusion profile is clear. The intense convection suppresses the rate of concentration increase along the sample length. A constantboundary-layer-model-type theory ${ }^{[46]}$ could be applied to model the axial segregation behavior. However, such a 
simplified model is not useful for understanding the lateral segregation behavior and its effect on the spacing disorder, especially in a system with poor mixing, as in the Al$\mathrm{Cu}$ system.

\section{Comparison with Experimental Results}

The numerical model shows that, although the convection will be present in both the $\mathrm{Al}-\mathrm{Cu}$ and $\mathrm{Pb}-\mathrm{Sn}$ systems, the intensity and modes of convection are quite different in these two systems. In the $\mathrm{Pb}-\mathrm{Sn}$ system, the rejection of lighter solute gives rise to a vigorous double-diffusive convection such that the composition profile alters in the axial direction, whereas no significant lateral solute variation occurs. Thus, the effect of convection will be to alter the magnitude of the primary spacing, but not the disorder in the primary spacing, since all cells or dendrites see the same thermal and concentration fields in the liquid. In contrast, the convection effects in the Al-Cu system show no appreciable axial segregation, but a large variation in solute in the radial direction. Consequently, different tips of cells or dendrites see different thermal and concentration gradients locally and, thus, result in different spacings along the radial direction. ${ }^{[21]}$ In addition, because of the variation in local spacings, each cell or dendrite has different interactions with its neighbors, thereby giving rise to a disorder in the array spacing.

In the $\mathrm{Pb}-\mathrm{Sn}$ system, the convection effects are vigorous and a constant-boundary-layer-model-type theory ${ }^{[46]}$ could be applied to characterize the concentration gradient at the interface. Since the concentration gradients at the different cell or dendrite tips are the same, the spacing will be more uniform, and the disorder observed would be similar to that predicted by the diffusive model. Note that partial mixing causes the primary spacing to be smaller in magnitude than that predicted by the diffusive model. In contrast, in the Al$\mathrm{Cu}$ system, the varying composition field ahead of cells and dendrites along the radial direction would cause significant disorder in the array spacing. Note that the concentration gradient is slightly higher at the wall than at the center (Figure 15 (b)), so that the boundary-layer width will decrease as we look at the cells from the center to the wall. This is equivalent to the effect of a larger velocity, so that the spacing near the wall will be smaller, as observed experimentally.

In the numerical model, the effects of convection and the morphology of the interface are decoupled by considering the interface to be flat, for determining the solute field. This approximation, however, seems to be valid when the curvature of the interface is not very large. ${ }^{[17]}$ By using the calculated variation in the composition at the interface in the radial direction and using the known value of the thermal gradient, the shape of the interface is reconstructed and compared with the experimentally observed shape in Figure 17 for a stationary interface. Note that a very good match is obtained except in the immediate vicinity of the wall, where there is a slight departure due to the surface-tension effect. Thus, the approximation of a flat interface for the examination of the effect of convection on the solute field is a good approximation for high G/V values. For low G/V values, where the curvature of the interface is very large, a rigorous model needs to be developed which couples convection with interface morphology. Such a model is quite complicated, although a basic framework has recently been

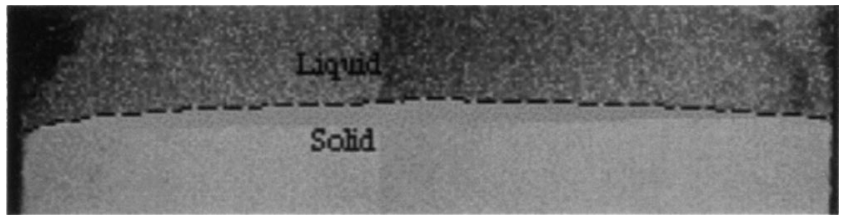

Fig. 17-Calculated liquid-solid interface shape (dotted line) and its comparison with the quenched interface of an Al-4.0 wt pct Cu sample. Modeling conditions and the experimental growth conditions are the same: hot zone temperature $-800{ }^{\circ} \mathrm{C}$, cold zone temperature $-22{ }^{\circ} \mathrm{C}$; translation velocity -0 ; sample size $-5.0 \mathrm{~mm}$; and alumina tube ampoule with a wall thickness of $1.5 \mathrm{~mm}$.

developed by Tong et $a .^{[45]}$ by using the phase-field approach.

Finally, it has been suggested that the spacing disorder in the two systems examined may not be due to convection, but due to the difference in physical properties of the two systems. ${ }^{[48]}$ Alloy parameters themselves will not give a planar and a highly curved interface in the two systems examined. The significant difference in microstructures obtained in these two systems cannot be explained by a diffusive-growth model, since these models can be normalized in terms of dimensionless parameters and would be self-similar. Such scaling laws have been discussed in the literature quite extensively, and they will not predict a highly curved and a planar cellular front. Only for a planar interface, in very thin samples (less than $50 \mu \mathrm{m}$ in diameter), will the contact-angle effects at the wall cause the interface to acquire curvature during growth. For cellular and dendritic microstructures, the main difference that breaks the scaling laws for different cells in an array is the presence of convection. In fact, microgravity experiments on cellular and dendritic growth have clearly shown that the interface becomes flat under a low-gravity environment in the $\mathrm{Al}-\mathrm{Cu}$ and $\mathrm{Al}-\mathrm{Ni}$ systems in which a heavier solute is present. Several experiments in thin samples, where convection effects are minimized, also show a planar, or not a curved, front. The alloy system is, of course, important, in that the property of the alloy determines the extent of convection, as we have shown in the two systems in which the density gradients in the axial direction have opposite signs and, thus, have different convective modes.

\section{CONCLUSIONS}

There are two major causes for the disorder in the spatial arrangement of cells or dendrites: (1) the spacing-selection criterion in the diffusive regime predicts a range of spacings that can be exhibited in an array, and (2) the mode of fluid flow in the liquid, which causes significant variations in the temperature and composition along the radial direction. The disorder is small in the diffusive-growth regime, whereas a large disorder is found when convection effects are present. For most experiments carried out on samples of $5 \mathrm{~mm}$ in diameter or larger in systems with heavier solute, the convection effect is found to be the dominant effect in giving rise to a large disorder in the array. A numerical model has been developed to study the effects of convection on primaryspacing disorder. It is shown that the disorder in spacing depends on the nature of convection present in the system. The convection effects that lead to radial segregation of 
solute at the interface tend to give a higher disorder. In the $\mathrm{Pb}-\mathrm{Sn}$ system, which is solutally unstable in the axial direction, an intense flow is present which produces large macrosegragation in the axial direction (Figure 14), but somewhat uniform conditions at the cell or dendrite tips in an array. Thus, the primary-spacing variation would be a minimum and would be similar to that predicted by the diffusive model. The actual spacing, however, will be significantly smaller than that predicted by the diffusive-growth model, since the partial mixing would reduce the width of the solute boundary layer.

In systems with heavier solute, it is shown that the fluidflow effect comes due to the presence of the radial temperature gradient which always exist in a vertical Bridgman system. Through experimental measurements and numerical modeling, it is observed that a $2{ }^{\circ} \mathrm{C}$ to $4{ }^{\circ} \mathrm{C}$ temperature difference can exist between the center and the edge of an Al-Cu sample. ${ }^{[17]}$ We have shown that the convective flow driven by this radial temperature gradient may not be intense, especially in the presence of an axially stabilizing solute gradient as in the case of $\mathrm{Al}-\mathrm{Cu}$ alloys, but causes significant lateral segregation in large samples $(\sim 6.0 \mathrm{~mm}$ in diameter). This lateral solute segregation alters the local conditions near the cell or dendrite tips in an array and gives rise to significant disorder in the array. The experimental results clearly show that the disorder in primary spacings is not directly related to the intensity of flow, but depends upon the specific nature of convection that is present in a system.

\section{ACKNOWLEDGMENTS}

This work was supported by NASA microgravity research, Division of Materials Science, Grant No. NASA NCC8-98. The authors acknowledge H. Jamgotchian and J.T. Mason for help in the statistical analysis of the results and H. Song and V.M. Kumar for help with the directional solidification work. A part of this work was carried out at Ames Laboratory, which is operated for the United States Department of Energy by Iowa State University, under Contract No. W7405-Eng-82, supported by the director of Energy Research, Office of Basis Energy Sciences.

\section{REFERENCES}

1. M.C. Flemings: Solidification Processing, McGraw-Hill, New York, NY, 1975.

2. J.A. Warren and J.S. Langer: Phys. Rev., 1990, vol. 42A, pp. 3518-25.

3. J.D. Hunt: Solidification and Casting of Metals, The Metals Society, London, 1979, Book 192, pp. 3-11.

4. J.D. Hunt and S. Lu: Metall. Mater. Trans., 1996, vol. 27A, pp. 611-23.

5. S.N. Tewari and R. Shah: Metall. Mater. Trans. A, 1996, vol. 27A, pp. 1353-62.

6. S.H. Han and R. Trivedi: Acta Metall. Mater. A, 1994, vol. 42, pp. 25-41.

7. W. Kurz and D.J. Fisher: Acta Metall., 1981, vol. 29, pp. 11-20.

8. M.A. Eshelman, V. Seetharaman, and R. Trivedi: Acta Metall., 1988, vol. 36 , pp. 1165-74.

9. K. Somboonsuk, J.T. Mason, and R. Trivedi: Metall. Trans. A, 1984, vol. $15 \mathrm{~A}$, pp. $967-75$

10. C.M. Klaren, J.D. Verhoeven, and R. Trivedi: Metall. Trans. A, 1980, vol. 11A, pp. 1853-61.

11. J.D. Verhoeven, J.T. Mason, and R. Trivedi: Metal Trans. A, 1986, vol. 17A, pp. 991-1000.

12. H. Esaka and W. Kurz: J. Cryst. Growth, 1985, vol. 72, pp. 578-84.

13. R. Trivedi and K. Somboonsuk: J. Mater. Sci. Eng., 1984, vol. 65, pp. 65-74.

14. H. Jamgotchian, B. Billia, and L. Capella: J. Cryst. Growth, 1983, vol. 64, pp. 338-44.

15. G. Grange, J. Gastaldi, C. Jourdan, and B. Billia: J. Cryst. Growth, 1995, vol. 151, pp. 192-99.

16. K. Miyata, T. Suzuki, and J.I. Uno: Metall. Trans. A, 1985, vol. 16A, pp. 1799-1805.

17. P. Mazumder: Ph.D. Thesis, Iowa State University, Ames, IA, 1999

18. R. Trivedi, H. Miyahara, P. Mazumder, E. Simsek, and S.N. Tewari: J. Cryst. Growth, 2001, vol. 222, pp. 365-79.

19. M.D. Dupouy, D. Camel, and J.J. Favier: Acta Metall., 1989, vol. 37, pp. 1143-57.

20. M.H. Burden, D.J. Hebditch, and J.D. Hunt: J. Cryst. Growth, 1973, vol. 20, pp. 121-24.

21. R. Trivedi, S. Liu, P. Mazumder, and E. Simsek: Sci. Technol. Adv Mater., 2001, vol. 2, pp. 309-16.

22. S.R. Coriell, M.R. Cordes, W.J. Boettinger, and R.F. Sekerka: J. Cryst. Growth, 1980, vol. 49, pp. 13-28.

23. C. Le Marek, R. Guerin, and P. Haldewnwag: J. Cryst. Growth, 1996, vol. 169, pp. 147-56.

24. T.H. Solomon, R.R. Hartley, and A.T. Lee: Phys. Rev. E, 1999, vol. 60, p. 3063.

25. G.K. Batchelor: Q. Appl. Math., 1954, vol. 12 (3), p. 209.

26. D.J. Tritton: Physical Fluid Dynamics, Oxford Science Publications, 1988.

27. P.M. Adornato and R.A. Brown: J. Cryst. Growth, 1987, vol. 80, pp. 155-90.

28. D.H. Kim and R.A. Brown: J. Cryst. Growth, 1989, vol. 96, pp. 609-27.

29. D.H. Kim and R.A. Brown: J. Cryst. Growth, 1991, vol. 114, pp. 411-34.

30. C.J. Chang and R.A. Brown: J. Cryst. Growth, 1983, vol. 63, pp. 343-65.

31. P. Mazumder and R. Trivedi: in Fluid Flow Phenomenon in Metal Processing, N. El-Kaddah, D.G.C. Robertson, S.T. Johansen, and V.P. Voller, eds., TMS, Warrendale, PA, 1999, pp. 459-56.

32. P. Mazumder and R. Trivedi: J. Fluid Mech., submitted for publication.

33. S.N. Tewari and R. Trivedi: Microgravity Sci. Technol., 1991, vol. 4, pp. 240-44.

34. D.G. McCartney and J.D. Hunt: Acta Metall., 1981, vol. 29, pp 1851-63.

35. H. Jacobi and K. Schwerdtfeger: Metall. Trans. A, 1976, vol. 7A, pp. 811-20.

36. B. Billia, H. Jamgotchian, and H. Nguyen Thi: Metall. Trans. A, 1991, vol. 22A, pp. 3041-50.

37. D. Weaire and N. Rivier: Contemp. Phys., 1984, vol. 25, p. 59.

38. C. Dussert, G. Rasigny, M. Rasigni, J. Palmari, and A. Llebaria: Phys Rev., 1986, vol. 34B, p. 3528

39. S.N. Tewari, Y.-H. Weng, G.L. Ding, and R. Trivedi: Metall. Mater. Trans. A, 2002, vol. 33A, pp. 1229-43.

40. C.S. Smith: Metal Interfaces, ASM, Metals Park, OH, 1952, pp. 65-113.

41. W. Peaceman and H.H. Rachford: J. Soc. Indust. Appl. Math., 1956, vol. 3 , p. 28 .

42. L. Lapidus and G.F. Pinder: Numerical Solution of Partial Differential Equations in Science and Engineering, John Wiley \& Sons, New York, NY, 1982.

43. R.A. Brown: AIChE J., 1988, vol. 34, pp. 881-911.

44. W.A. Tiller, K.A. Jackson, J.W. Rutter, and B. Chalmers: Acta Metall., 1953, vol. 1, pp. 428-37.

45. P. Capper, C.L. Jones, E.J. Pearce, and M.J.T. Quelch: J Cryst. Growth, 1983, vol. 62, pp. 487-97.

46. J.A. Burton, R.C. Prim, and W.P. Slichter: J. Chem. Phys., 1953, vol. 21, pp. 1987-91

47. X. Tong, C. Beckermann, and A. Karma: Phys. Rev. E, 2000, vol. 61, pp. R49-R52.

48. Reviewer of the paper. 